\title{
AXONAL TRANSPORT OF AN INSULIN-LIKE PEPTIDE MRNA \\ PROMOTES STRESS RECOVERY IN C. ELEGANS
}

\author{
Rashmi Chandra, Lisa Li\#, Zahabiya Husain\#, Shashwat Mishra, and Joy Alcedo* \\ Department of Biological Sciences, Wayne State University, Detroit, MI 48202, USA
}

\#Equal contributions

*Correspondence to: joy.alcedo@wayne.edu

Tel. no: +1313 5773473 


\begin{abstract}
Aberrations in insulin or insulin-like peptide (ILP) signaling in the brain causes many neurological diseases. Here we report that mRNAs of specific ILPs are surprisingly mobilized to the axons of C. elegans during stress. Transport of the ILP ins-6 mRNA to axons facilitates recovery from stress, whereas loss of axonal mRNA delays recovery. In addition, the axonal traffic of ins- 6 mRNA is regulated by at least two opposing signals: one that depends on the insulin receptor DAF-2 and a kinesin-2 motor; and a second signal that is independent of DAF-2, but involves a kinesin-3 motor. While Golgi bodies that package nascent peptides, like ILPs, have not been previously found in C. elegans axons, we show that axons of stressed C. elegans have increased Golgi ready to package peptides for secretion. Thus, our findings present a mechanism that facilitates an animal's rapid recovery from stress through axonal ILP mRNA mobilization.
\end{abstract}




\section{INTRODUCTION}

The inability to recover from stress predisposes us to many neurological dysfunctions, such as post-traumatic brain injuries and neurodegeneration [reviewed in (Blázquez et al., 2014; Esch et al., 2002; Frey, 2013; Koenen et al., 2008; Zeng et al., 2016)]. Here we use the worm C. elegans to elucidate the mechanisms of stress adaptation and recovery, since the worm can switch its physiological state in response to stress [reviewed in (Riddle and Albert, 1997)]. Like in humans [(Blessing et al., 2017; Marcovecchio and Chiarelli, 2012); reviewed in (Bedse et al., 2015; Blázquez et al., 2014; Boucher et al., 2014; Frey, 2013; Zeng et al., 2016)], insulin-like peptides (ILPs) and their receptor enable the worms to endure and recover from stress (Kimura et al., 1997; Riddle and Albert, 1997).

In C. elegans, environmental stressors, like food scarcity and high population density, cause the first larval (L1) stage of reproductive growth to form dauers, the stress-induced arrested alternative to the third-stage larva (L3) of the growth program (Golden and Riddle, 1984). Compared to an L3, a dauer is more stress-resistant (Riddle and Albert, 1997). When dauers sense the return of favorable environments, they exit into the last larval (L4) stage and become a reproductive adult (Golden and Riddle, 1984; Riddle et al., 1981). These developmental switches are controlled by the combinatorial activities of specific ILPs from specific neurons (Bargmann and Horvitz, 1991; Cornils et al., 2011; Fernandes de Abreu et al., 2014; Li et al., 2003; Pierce et al., 2001; Schackwitz et al., 1996).

The C. elegans ILPs exist as a large family of peptides with 40 members ( Li et al., 2003; Pierce et al., 2001), which are organized into a network where one ILP regulates the expression of other ILPs (Fernandes de Abreu et al., 2014). This inter-ILP network coordinates distinct subsets of ILPs that either regulate entry into or exit from dauer arrest (Cornils et al., 2011; Fernandes de Abreu et al., 2014). A major node of the network is the ILP ins-6, because ins-6 expression is affected by the highest number of ILPs and ins- 6 in turn affects the expression of many other ILPs (Fernandes de Abreu et al., 2014). This is consistent with the highly pleiotropic 
phenotype of ins-6, which is also a major regulator of stress recovery (Chen et al., 2013; Cornils et al., 2011; Fernandes de Abreu et al., 2014).

Previously, we have shown that ins-6 acts from ASJ sensory neurons to promote exit from the dauer state (Cornils et al., 2011). In this study, we have discovered that upon dauer arrest, ins-6 mRNA is surprisingly transported to ASJ axons. Because we observe axonal ins-6 mRNA only in dauers, we have investigated the significance and mechanism of axonal ILP mRNA transport in response to stress. We show that mRNAs of ILPs that promote dauer exit are trafficked to axons and that axonal ins- 6 mRNA promotes rapid dauer recovery. This is further supported by our finding that dauers also have enhanced axonal mobilization of Golgi bodies that can locally package ILP mRNA products for prompt secretion from axonal compartments.

Insulin signaling is conserved between worms and humans [reviewed in (Alcedo and Zhang, 2013)]. Stress also influences insulin, insulin growth factor and ILP relaxin mRNAs that are expressed in the human brain [reviewed in (Blázquez et al., 2014; Fernandez and TorresAleman, 2012; Wilkinson et al., 2005)]. Thus, our study raises the possibility that stress-induced axonal transport of ILP mRNAs and Golgi bodies in the worms is also present in humans to facilitate stress recovery.

\section{RESULTS}

\section{The insulin-like peptide ins-6 mRNA is trafficked to dauer axons}

The decision between reproductive growth and stress-induced dauer arrest is regulated by specific sensory neurons, many of which are found in the amphid organ [Figure S1A; (White et al., 1986)]. For example, the amphid chemosensory neurons ASI and ADF act redundantly to inhibit entry into dauer arrest under non-stress environments (Bargmann and Horvitz, 1991). In contrast, the amphid chemosensory neuron ASJ has two opposing functions-it promotes dauer entry in response to stress and it promotes dauer exit under improved environments (Bargmann and Horvitz, 1991; Schackwitz et al., 1996). These neurons send their axons to a structure called 
the nerve ring (NR) bundle (Figure $S 1 A$ ), where the axons synapse to each other (White et al., 1986).

These amphid neurons express ILPs that regulate the switches between reproductive growth and dauer arrest (Cornils et al., 2011; Fernandes de Abreu et al., 2014; Li et al., 2003; Pierce et al., 2001). One of these ILPs is ins-6, which has a minor role in inhibiting dauer entry and a major role in facilitating exit from dauer after environments improve (Cornils et al., 2011; Fernandes de Abreu et al., 2014). Consistent with its function, we found through fluorescent in situ hybridization (FISH) that during the dauer entry decision stage (L1), endogenous ins-6 mRNA was in the ASI neuronal soma, where it remained expressed in later stages (Figures 1, S1B-S1H). In a few second-stage larvae (L2s), ins-6 also started to be expressed in the soma of the neuron ASJ (Figure 1B, 1B', 1E-1F), where ins-6 persisted as the animal developed into L3 and L4 (Figures 1C-1D, 1C'-1D', 1E-1F, S1D-S1H).

However, in dauers induced by high population density and starvation, ins-6 mRNA was lost in ASI, but found in the ASJ soma and intriguingly in the NR axon bundle (Figures $2 A, 2 B$, $\left.2 A^{\prime}, 2 B^{\prime}, 2 E, S 2 A\right)$. To confirm that the NR signal was specific to ins- 6 mRNA, we performed FISH on ins- 6 deletion mutant dauers and found that the ins- 6 NR signal was reduced to background in these mutants (Figures $2 C, 2 C, 2 E, S 2 A$ ). We showed that ins-6 mRNA in the NR was transported from the ASJ soma, since dauers that had genetically-ablated ASJ neurons also had background levels of the ins-6 mRNA signal in the NR (Figures 2D, 2D, 2E, S2A). The presence of ins- 6 mRNA in the ASJ axonal tract further supported the idea that ins- 6 mRNA was trafficked from the soma (Figure $2 F, 2 G$ ). While the NR signal of ins- 6 mRNA was diffuse and broader than expected (Figure $2 A-2 B, 2 A^{\prime}-2 B^{\prime}$ ), this signal resembled the broad signal, after the FISH protocol, of a GFP protein (Figure $2 \mathrm{H}, 2 \mathrm{H}^{\prime}$ ) that is expressed in only two pairs of axons (Li et al., 2003). We found that paraformaldehyde fixation and treatment with the hybridization buffer damaged the NR axonal fibers (Figure 2l, 2l'), which likely caused the scattering of the GFP protein or the fluorescent-labeled mRNAs from the axonal sources to the neighboring axons of the NR bundle. 
Wild-type dauers can be divided into two classes: class A represents dauers that have higher ins- 6 mRNA in the cell body, whereas class B are dauers that have higher ins- 6 in the axons (Figures $2 A, 2 B, 2 E, S 2 A$ ). Because starvation-induced dauers had ins- 6 mRNA in the NR (Figure 2), we then tested whether starvation alone was sufficient to traffic ins-6 mRNA. While starvation reduced endogenous ins- 6 mRNA in both ASI and ASJ neurons, none of the starved larvae showed any ins- 6 mRNA in the NR (Figure S2B-S2E). Thus, the switch to the dauer state is required to traffic ins- 6 mRNA to axons. Once dauers exit to the last larval stage (post-dauer [PD] L4s), ins-6 mRNA was also lost in the NR, but found in the ASJ soma of all animals and in the ASI soma of some animals (Figure S1G-S1H). Together our data suggest that axonal ins-6 mRNA transport occurs only under certain stressed conditions, such as dauers.

\section{Dauer-exit promoting ILP mRNAs are in axons}

Next, we asked whether all dauer-specific mRNAs are trafficked to the NR. We determined the dauer-dependent mRNA localization for other ILPs that regulate the switches between reproductive growth and dauer arrest (Cornils et al., 2011; Fernandes de Abreu et al., 2014). Like ins-6, the ILP daf-28 inhibits dauer entry and promotes dauer recovery (Cornils et al., 2011; Fernandes de Abreu et al., 2014; Kao et al., 2007; Li et al., 2003). Similar to ins-6, we found that daf-28 mRNA was present in the axons of wild-type dauers (Figure $3 B, 3 B^{\prime}$ ) and absent in daf-28 deletion mutant dauers (Figure $3 C, 3 C^{\prime}$ ). Again, wild-type dauers can be divided into different classes based on the subcellular localization of daf-28 mRNA. Class A dauers showed more daf-28 mRNA in the somas of ASI and ASJ neurons (Figure $3 A, 3 A^{\prime}$ ); class B dauers showed more daf-28 mRNA in the NR axon bundle (Figure 3B, 3B). However, unlike class B ins-6expressing animals, the class B daf-28-expressing animals were enriched in wild-type young dauers (2-day old; Figure 3D). About $78 \%$ of young dauers already had high levels of daf-28 mRNA in the NR, whereas only $36 \%$ of this population had high levels of NR ins- 6 mRNA (Figure $3 D, 3 E)$. On the other hand, older wild-type dauers (5-day old) had decreased class B daf-28- 
expressing animals and increased class B ins-6-expressing animals (Figure 3D). Together these data show that both daf-28 and ins- 6 mRNAs are trafficked to the dauer NR, but at different time points.

Unlike the NR axon bundle of young wild-type dauers, older dauers also had significantly less daf-28 or ins-6 mRNA in these axons (Figure 3E). In older wild-type animals, we observed the appearance of a third class of dauers in the population: the class $\mathrm{C}$ dauers that lack daf-28 mRNA (Figure 3D-3E), which indicates that some ILP mRNAs are progressively lost in older dauers. Yet, the longer perdurance of ins- 6 mRNA than daf-28 mRNA in the dauer NR (Figure $3 E$ ) highlights a more significant role for ins-6 mRNA than daf-28 in these axons. We previously showed that ins-6 has a more important role in dauer exit than daf-28 (Cornils et al., 2011), which suggests that the axonal transport of ins- 6 and daf-28 mRNAs is to expedite dauer exit.

In support of this hypothesis, we found that the mRNAs of proteins that do not promote dauer exit were not trafficked to the NR [Figures 3D, S3; (Cornils et al., 2011)]. The mRNA of the ILP ins-1, which inhibits dauer exit (Cornils et al., 2011), was either expressed in the somas of multiple neurons (Class $\mathrm{A} 1$; Figure $\mathrm{S} 3 \mathrm{C}$ ) or in the soma of a single neuron in wild-type dauers (Class A2; Figure S3D). While the number of neuronal somas that express ins-1 decreased in older dauers (Figure $S 3 A$ ), we did not detect ins-1 mRNA in any dauer NR (Figures $3 D$, S3B$S 3 E)$.

Using animals that express GFP in the dauer ASI and ASJ neurons (Li et al., 2003), we also determined the location of gfp mRNA in these neurons. Since GFP plays no role in dauer exit, our hypothesis above predicts the absence of gfp mRNA in the dauer NR. Indeed, we observed no gfp mRNA in the NR, despite the presence of the GFP protein in these processes (Figure S3F-S3F'; see also Figure 6C, 6C'). Thus, lack of axonal ins-1 and gfp mRNAs and presence of dauer-exit promoting ILP mRNAs in the NR suggest that axonal mRNA transport is required for dauer recovery. 


\section{Insulin signaling and specific kinesins regulate axonal ins-6 mRNA transport}

To test our hypothesis, we asked how axonal trafficking of ins-6 mRNA is regulated, which should also allow us to manipulate axonal ins- 6 mRNA levels and assess their effects on dauer recovery. The ILP receptor DAF-2 was previously shown to promote dauer exit (Gems et al., 1998). At 25ㄷ, the daf-2(e1368) mutation leads to formation of dauers that exit after a few days, while the daf-2(e1370) mutation is a stronger allele that produces constitutive dauer arrest (Gems et al., 1998). We analyzed the axonal ins- 6 mRNA levels in dauers of both daf- 2 alleles at $25^{\circ} \mathrm{C}$. We focused on 3-day old dauers, since wild type at this age at $25^{\circ} \mathrm{C}$ showed a distribution of class $\mathrm{A}$ and class B ins-6-expressing dauers comparable to 5-day old wild type at $20^{\circ} \mathrm{C}$ (Figure 4). Compared to wild-type dauers, we found that both daf-2 mutants had much fewer class B dauers (Figures $4 A, S 4 A)$. The lack of exit in daf-2(e1370) dauers at $25^{\circ} \mathrm{C}$ (Gems et al., 1998) is likely due to loss of ins- 6 mRNA in some of these animals, since we also observed the emergence of class $C$ dauers that had no ins- 6 expression in the ASJ soma and NR (Figure 4A). Thus, the wildtype DAF-2 receptor stimulates ins- 6 mRNA transport to the NR to induce dauer recovery.

Axonal transport depends on kinesins, which are the motors that carry cargo along the microtubules that run the length of an axon [reviewed in (Scholey, 2013; Siddiqui, 2002)]. C. elegans has multiple kinesins, some of which are expressed in neurons (Scholey, 2013; Siddiqui, 2002). Two of these kinesins represent members of the kinesin-1 and kinesin-2 families, which have been implicated in transporting mRNAs to different subcellular compartments in other animals (Kanai et al., 2004; Messitt et al., 2008). In C. elegans, unc-116 is a kinesin-1 motor, osm-3 is a kinesin-2 motor, and both kinesins are present in ASJ (Sakamoto et al., 2005; Scholey, 2013; Tabish et al., 1995). In unc-116 or osm-3 loss-of-function mutants, class B ins-6-expressing dauers are lost (Figures 4B, S4B), which indicates that wild-type unc-116 and osm-3 are required in transporting ins-6 mRNA to dauer axons. The rescue of osm-3 in ASJ alone, jxEx194 and jxEx195, also rescued the class A and class B distributions of ins-6-expressing dauers, which shows that OSM-3 kinesin acts in ASJ to mobilize ins-6 mRNA to axons (Figures $4 \mathrm{C}, \mathrm{S} 4 \mathrm{C}$ ). 
Next, we asked if neuronal kinesins that are absent from ASJ also exert a similar effect on ins-6 mRNA, such as klp-6, which is a kinesin-3 motor (Peden and Barr, 2005). Interestingly, a partial loss-of-function mutation in klp-6 (Peden and Barr, 2005) led to an enrichment in class B ins-6-expressing dauers (Figures $4 B, S 4 B$ ), which suggests that wild-type klp-6 inhibits ins-6 mRNA transport. Because KLP-6 is not in ASJ (Peden and Barr, 2005), this suggests that the klp-6-dependent regulation of axonal ins-6 mRNA involves a signal secreted from klp-6expressing cells. Considering the daf-2-dependence of ins- 6 mRNA transport (Figures $4 A, S 4 A$ ), this signal might be another ILP that is a DAF-2 receptor ligand.

Yet, the epistasis between daf-2 and klp-6 implies the involvement of more than one signal (Figures $4 D, S 4 D$ ). Similar to $20^{\circ} \mathrm{C}, k l p-6$ single mutants again had more class $\mathrm{B}$ ins-6-expressing dauers at $25^{\circ} \mathrm{C}$, unlike daf-2 single mutant or wild-type dauers under the same conditions (Figures $4 D, S 4 D)$. In contrast, the daf-2 klp-6 double mutants exhibited the wild-type dauer distribution phenotype (Figures $4 D$, S4D). Since the daf-2 klp-6 double mutants showed an intermediate phenotype between those of daf-2 and klp-6 single mutants (Figures $4 D, S 4 D$ ), this implicates a second signal that acts parallel to the DAF-2 ligand in the klp-6-dependent inhibition of axonal ins-6 mRNA transport.

In comparison, the kinesin OSM-3 likely functions downstream of the DAF-2 receptor. As at $20^{\circ} \mathrm{C}$, the severe osm-3 single mutants again lost class $\mathrm{B}$ ins-6-expressing dauers at $25^{\circ} \mathrm{C}$, which resembled daf-2 single mutants (Figures 4D, S4D). Similar to the stronger daf-2(e1370) single mutant (Figures 4A, S4A), the daf-2(e1368); osm-3 double mutants produced class $\mathrm{C}$ dauers that lost all ins-6 expression (Figures 4D, S4D). However, the ASJ-specific rescue of osm-3 in the daf-2(e1368); osm-3 double mutants restored the wild-type class A and class B distributions of ins-6-expressing dauers (Figures $4 D, S 4 D$ ). This suggests that OSM-3 activity in ASJ is downstream of DAF-2 in promoting ins- 6 mRNA transport to dauer axons.

\section{Axonal ins-6 mRNA levels modulate dauer recovery}


The altered ins-6 mRNA distribution in the different mutants allowed us to test the significance of axonal ins- 6 mRNA on dauer recovery. Because daf-2(e1368) mutant dauers exit after a few days (Gems et al., 1998), we analyzed the dauer recovery of daf-2(e1368) in the presence versus absence of the wild-type kinesins that regulate axonal ins- 6 mRNA levels. The mutations in kinesins osm-3 and unc-116, which failed to transport ins-6 mRNA axonally (Figures 4B-4D, S4), significantly delayed the exit of daf-2(e1368) dauers (Figure 5A, Table S1). The ASJ-specific rescue of osm-3, which restored the high axonal ins-6-expressing class B dauers (Figures $4 D$, S4), also rescued the delayed dauer exit of daf-2; osm-3 double mutants back to the exit phenotype of daf-2 single mutants (Figure 5C, Table S1). These suggest that axonal ins-6 mRNA expedites dauer recovery.

Indeed, loss of $k l p-6$, which enriched for the high axonal ins-6-expressing dauer population (Figures 4B, 4D, S4), caused daf-2(e1368) mutant dauers to exit earlier to L4 (Figure 5B, Table S1). Interestingly, both the daf-2; osm-3 double mutants that have wild-type osm-3 in ASJ and the daf-2 klp-6 double mutants showed similar distributions of class A and class B ins-6expressing dauers (Figures 4D, S4), but different dauer exit phenotypes compared to daf-2 single mutants (Figure 5B-5C, Table S1). This implies that the presence of axonal ins-6 mRNA in dauers is only one of the requirements needed to induce exit. However, because restoring class B ins-6expressing dauers to a population accelerated dauer exit [compare (i) daf-2; osm-3; jxEx194 or jxEx195 transgenic animals to daf-2; osm-3 non-rescued double mutants or (ii) daf-2 klp-6 double mutants to daf-2 single mutants], this highlights the importance of axonal ins- 6 mRNA in dauer recovery.

\section{Untranslated regions of ins- 6 are partly necessary for its mRNA transport}

Untranslated regions (UTRs) control gene expression [reviewed in (Decker and Parker, 1995)] through mRNA stability (Brown et al., 1993; Scheper et al., 1995) and/or subcellular localization (Bertrand et al., 1998; Gunkel et al., 1998; Thio et al., 2000). Since ins-6 mRNA has both 5' and 
3' UTRs (Figure 6A), we asked if axonal trafficking of ins-6 mRNA requires its UTRs. We generated constructs that lacked both 5' and 3' UTRs of ins-6 (Figure 6A) and compared their mRNA localization, $j \times E x 196$ and $j \times E x 197$, with the mRNA localization of constructs that carry the whole ins-6 genomic locus, jxEx27 and jxEx28 (Figure 6A), in the ins-6 deletion background (Figure 6B). The full ins-6 genomic locus, jxEx27 or jxEx28, rescued the ins-6 deletion phenotype back to wild type (Figure 6B). In contrast, the UTR-less constructs, jxEx196 or jxEx197, only partly rescued the ins-6 mutant phenotype (Figure 6B), which show that UTRs modulate ins-6 mRNA levels. Since these animals also exhibited class B dauers (Figure 6B), then loss of UTRs still allows ins- 6 mRNA transport to axons. However, the UTR-less animals had significantly fewer class $B$ dauers than the full-rescue ins-6 lines (Figure $6 B$ ), which means that UTRs are at least partly necessary for axonal ins-6 mRNA.

Next, we asked if ins-6 UTRs are sufficient to carry any mRNA to dauer axons. gfp mRNA alone was not trafficked to dauer axons, whether gfp was expressed from ASI and ASJ (Figure S3F-S3F') or from ASJ only (jxEx187; Figure $\left.6 A, 6 C, 6 C^{\prime}\right)$. We tagged gfp mRNA with the ins-6 5' and 3' UTRs and expressed it from ASJ (jxEx190; Figure 6A). Although the GFP protein can be found in the dauer axons, the gfp-ins-6 UTR mRNA hybrid remained in the ASJ soma (Figure $\left.6 D, 6 D^{\prime}\right)$. Thus, while ins-6 UTRs are partly necessary to traffic ins- 6 mRNA to axons, the UTRs are insufficient for axonal mRNA transport.

\section{Stress enhances Golgi mobilization to axons}

Like other secreted proteins, ILP mRNAs need to be processed and packaged for secretion, but previous literature only reported the presence of rough endoplasmic reticulum in wild-type $C$. elegans axons (Edwards et al., 2013). We determined if C. elegans axons also contain Golgi that would be needed to package locally translated peptides. We used a pan-neuronally expressed YFP-tagged Golgi marker, a-mannosidase II [aman-2; (Edwards et al., 2013; Sumakovic et al., 2009)]. C. elegans larvae, like dauer and its alternative form, L3, have Golgi in neuronal somas, 
dendrites, and axons, which include the dorsal cord axons and NR, but not the commissures (Figure 7, Videos 1-2). Notably, dauers had more axonal Golgi (Figure 7E, Video 2), which suggests that stress increases Golgi mobilization to process newly synthesized proteins in axons.

\section{DISCUSSION}

Aberrant insulin signaling hampers recovery from stress. Because insulin signaling ensures homeostasis (Blázquez et al., 2014; Fernandes de Abreu et al., 2014), ligands for this pathway undergo multiple levels of regulation to enable the pathway to function with high precision (Fu et al., 2013). While the significance of ILP mRNA subcellular localization has yet to be considered, we show that certain stressors localize mRNAs of specific ILPs through distinct kinesin activities to $C$. elegans axons, which is accompanied by an increase in axonal Golgi mobilization. Importantly, our study suggests that these ILP mRNAs must be in the axons and locally translated and packaged for prompt secretion to facilitate stress recovery. This illustrates a novel mechanism where ILP mRNAs maintain neuronal plasticity during stress.

\section{Certain ILP mRNAs are localized to axons by specific stressors to promote recovery}

The environment alters ins- 6 expression at the transcriptional and post-transcriptional levels. ins- 6 is first expressed in one pair (ASI) and later in two pairs (ASI and ASJ) of sensory neurons under optimal environments (Figures 1, S1). Like other ILP mRNAs that are present in neuronal somas of Drosophila and vertebrate brains (Banerjee et al., 2010; Bathgate et al., 2013; Brogiolo et al., 2001; Broughton et al., 2005; Ma et al., 2009), ins-6 mRNA is in ASI and ASJ somas under nonstress conditions. In starvation-induced dauers, ins-6 is off in ASI, but remains expressed in ASJ. Importantly, ins-6 mRNA is mobilized to dauer ASJ axons. This ILP mRNA localization presumably leads to a prompt resetting of homeostasis after a major environmental fluctuation.

Yet, why do we see axonal ins-6 mRNA in dauers (Figure 2), but not in starved non-dauers (Figure S2B-S2E)? This is likely because the dauer itself is an adaptive response that the animal 
uses to survive a potentially protracted, harsh environmental change, as it awaits a better environment (Riddle and Albert, 1997). For this reason, the dauer program should include a priming mechanism that promotes recovery. The axonal transport of an ILP mRNA, whose peptide product is required for dauer exit, could serve as a priming mechanism. Because dauers have decreased global transcription (Dalley and Golomb, 1992; Wang and Kim, 2003), the local translation of a previously existing mRNA will lead to a faster response to improved environments. This is important, since a prolonged stay in the dauer state can lead to deficits in animals that eventually exit (Kim and Paik, 2008). Thus, it is not surprising that the mRNAs of ILPs that promote exit are the mRNAs that are localized to axons (Figures 2, 3), whereas mRNAs of proteins that do not promote exit (Cornils et al., 2011) are absent in axons (Figure S3).

The difference in temporal axonal mRNA localization patterns for ins-6 and daf-28 (Figure $3 D-3 E$ ) hint at different exit requirements for young versus old dauers. However, the longer perdurance of axonal ins- 6 mRNA than daf-28 mRNA (Figure 3D-3E) is consistent with the larger role of ins- 6 versus daf-28 in promoting dauer recovery (Cornils et al., 2011). An increase in axonal ins- 6 mRNA in a dauer population enhances exit, whereas a decrease in axonal ins- 6 mRNA delays exit (Figures 4, S4, 5, Table S1). As an animal that has recovered from dauer also shows no axonal ins-6 mRNA (Figure S1G-S1H), this indicates that ins- 6 mRNA is not needed in axons in post-recovery, further highlighting the significance of axonal ILP mRNA in stressed animals.

\section{Insulin signaling regulates the mRNA localization of at least one of its ligands}

Insulin receptor activity promotes mRNA expression (Fernandes de Abreu et al., 2014; Kaplan et al., 2019; Leibiger et al., 1998; Li et al., 2003; Murphy et al., 2003), translation (Lee et al., 2012), and secretion of some of its ligands (Kulkarni et al., 1999) across species. Here we show that insulin receptor activity also promotes the mobilization of the mRNA of at least one of its ligands to specific subcellular compartments, e.g., the C. elegans axons (Figures 4, S4). This positive 
feedback regulation in insulin signaling allows the rapid responses (Kaplan et al., 2019) that are necessary in switching from one state to another, such as exit from dauer to post-dauer state.

The C. elegans insulin receptor DAF-2 stimulates dauer exit (Gems et al., 1998), at least by regulating the fate of ins- 6 mRNA (Figures 4,54 ). Our data suggest that DAF-2 signaling activates OSM-3 kinesin in ASJ to promote ins-6 mRNA traffic to axons (Figures 4, S4), which facilitates dauer exit (Figure 5B-5C, Table S1). Intriguingly, animals that have the weak loss-offunction daf-2(e1368) and the strong osm-3 loss of function also show the more severe phenotype of the strong daf-2 loss-of-function mutant $e 1370$, where some dauers have lost ins-6 expression in both soma and axon (Figures 4, S4). This suggests that both DAF-2 and OSM-3 have two roles: one is to promote axonal ins- 6 mRNA transport and the other is to inhibit loss of ins- 6 mRNA. While this is similar to the function of ins- 6 UTRs, which are partly required for ins- 6 mRNA transport and steady-state levels (Figure 6), it remains to be seen if OSM-3 is the kinesin that mobilizes ins-6 mRNA to axons via the ins-6 UTRs in response to DAF-2 signaling.

It must be noted that axonal ins- 6 mRNA is only one of the requirements for dauer exit. Wild-type OSM-3 in ASJ rescues the severe delay in dauer exit of daf-2; osm-3 double mutants back to the exit phenotype of daf-2 single mutants (Figure 5C, Table S1), although the rescued double mutants have axonal ins-6 mRNA brought back to wild-type levels (Figures $4 D, S 4 D$ ). Nonetheless, the importance of axonal ins- 6 mRNA in dauer recovery is evident in the enhanced exit of dauers (Figure 5B-5C, Table S1) to which axonal ins-6 mRNA is restored (Figures $4 D$, $S 4 D)$.

Our data also suggest that the daf-2-dependent axonal localization of ins- 6 mRNA in ASJ is antagonized by a daf-2-independent, but klp-6-dependent signal that is secreted from other neurons (Figures $4 D, S 4 D$ ). The regulation of axonal ins- 6 mRNA transport by these opposing signals underscores the idea that ins- 6 mRNA must be in axons only when needed, such as when the animal has to prepare for exit into a much better environment that supports survival. 


\section{Transport of Golgi bodies to larval axons increases with stress}

The mRNAs transported to axons are believed to be locally translated to expedite protein processing near the synaptic zone [reviewed in (Holt and Schuman, 2013; Jansen, 2001)], but an ILP peptide also needs to be packaged from Golgi prior to its secretion. In support of axonal translation, the rough endoplasmic reticulum has been found in axons of $C$. elegans and other animals [(Edwards et al., 2013); reviewed in (Spaulding and Burgess, 2017)]. In contrast, axonal Golgi has been rarely reported in other species (Morest, 1971; Wigglesworth, 1960; Willis et al., 2011) and has not been observed in adult C. elegans (Edwards et al., 2013). Interestingly, Golgi is in Drosophila larval axons (Cao et al., 2014), which suggests that C. elegans larvae will also have axonal Golgi. Indeed, we find Golgi in the axons of L3 and at much higher levels in the axons of dauers (Figure 7, Videos 1-2), which suggests that stress increases axonal Golgi mobilization.

Why should C. elegans larvae have axonal Golgi? Axonal translation is important in axon migration and synaptogenesis (Holt and Schuman, 2013). In C. elegans, synapse formation along the length of axons and axon outgrowth continue during larval stages [(Gujar et al., 2017; Lipton et al., 2018; Shen and Bargmann, 2003; White et al., 1978; White et al., 1986; Zhao and Nonet, 2000); reviewed in (Chisholm et al., 2016)]. These might require axonal Golgi to package the necessary proteins in larvae (Colón-Ramos et al., 2007; Shen and Bargmann, 2003).

The dauer axons can also be remodeled (Schroeder et al., 2013), which can lead to synaptogenesis. Since dauers have reduced global transcription (Dalley and Golomb, 1992; Wang and Kim, 2003), it is possible that a number of mRNAs, besides those involved in stress recovery, are axonally trafficked. The packaging of locally translated membrane or secreted proteins that promote axon outgrowths, synaptogenesis, and stress adaptation and recovery will require the presence of axonal Golgi. Thus, increased mobilization of Golgi and specific ILP mRNAs to dauer axons is a needed response in stress adaptation and recovery. This suggests a mechanism that promotes plasticity during stress and allows for optimal recovery from stress, a mechanism that might be conserved across metazoans. 


\section{MATERIALS AND METHODS}

\section{Experimental model}

Wild-type (N2) or mutant C. elegans hermaphrodites were grown at $20^{\circ} \mathrm{C}$ or $25^{\circ} \mathrm{C}$, as indicated, using standard protocols (Brenner, 1974; Cornils et al., 2011). Worms were grown on E. coli OP50 before each assay. Dauers were induced naturally through overcrowding and starvation (Golden and Riddle, 1984), except for the daf-2 mutants that routinely form dauers in the presence of abundant food at $25^{\circ} \mathrm{C}$ (Gems et al., 1998). All worm mutants in this study were backcrossed at least four times to our lab N2 strain before any analysis was performed, including the ASJ-ablated animals that have the trx-1p::/CE transgene (Cornils et al., 2011) integrated into their genome (generous gift of Miriam Goodman).

Transgene constructions. To generate an ASJ-specific rescue of osm-3, we drove the expression of a GFP-tagged osm-3 cDNA from an ASJ-specific promoter [pQZ93; (Cornils et al., 2011)]. We replaced the srh-114 promoter of OSM-3::GFP in the pAGB060 plasmid (generous gift from Piali Sengupta) with the ASJ-specific trx-1 promoter (Cornils et al., 2011; MirandaVizuete et al., 2006). To generate the UTR-less ins-6 transgene (pQZ97), we deleted the 72-bp 5' UTR and $110 \mathrm{bp}$ from the 3' UTR of the full ins-6 rescuing construct pQZ11 (Cornils et al., 2011). The polyA signal was kept at the 3' UTR of pQZ97. To create the ASJ-specific GFPexpressing lines with the ins-6 5' and 3' UTRs (pQZ91), we fused the 72-bp ins-6 5' UTR to the 5' end of the GFP cDNA in pQZ34, which used the trx-1 promoter to drive GFP expression (Figure 6A) from the vector backbone of pPD95.77 (generous gift from Andrew Fire). We also inserted the 124-bp ins-6 3' UTR to the 3' end of the GFP cDNA in pQZ34 (Figure 6A).

Transgenic worms. To create the ASJ-specific osm-3 rescue lines, we injected $25 \mathrm{ng} / \mu \mathrm{l}$ of pQZ93 with $25 \mathrm{ng} / \mu \mathrm{l}$ of the coinjection marker ofm-1::gfp into osm-3(p802) mutants. The two resulting independent lines, jxEx194 and jxEx195, were also crossed to daf-2(e1368) to generate 
the daf-2; osm-3 double mutants, in which osm-3 was rescued from the ASJ neurons. To determine the effects of the ins- 6 UTRs on the ins- 6 mRNA subcellular localization, we created the lines $j \times E x 196$ and $j \times E x 197$ by injecting $2 \mathrm{ng} / \mu \mathrm{l}$ of pQZ97 with $25 \mathrm{ng} / \mu \mathrm{l}$ of the coinjection marker ofm-1::gfp into ins-6(tm2416) mutants. These were compared to the full ins-6 rescuing lines jxEx27 and jxEx28, which were injected with $2 \mathrm{ng} / \mu \mathrm{l}$ of $\mathrm{pQZ11}$ and $25 \mathrm{ng} / \mu \mathrm{l}$ of the coinjection marker ofm-1::gfp into the ins-6(tm2416) mutants (Cornils et al., 2011). The coinjection marker ofm-1::gfp (25 ng/ $\mu \mathrm{l})$ has little or no effect on ins-6 mRNA subcellular localization (Figure $6 B$ ) or dauer exit [Table S1; (Fernandes de Abreu et al., 2014)].

To test the sufficiency of the ins- 6 UTRs in trafficking ins- 6 mRNA to the axons, we injected $50 \mathrm{ng} / \mu \mathrm{l}$ of pQZ91 into the wild-type background, generating the extrachromosomal line jxEx190. This was compared to the extrachromosomal line jxEx187, which has been injected with $50 \mathrm{ng} / \mu \mathrm{l}$ of pQZ34 into the wild-type background and lacks the ins-6 3' UTRs.

To confirm that dauer axons have Golgi bodies that can package newly synthesized INS-6 peptides, we injected $5 \mathrm{ng} / \mu \mathrm{l}$ of the pan-neuronal rab-3p::aman-2::yfp plasmid (generous gift of Stefan Eimer) with $25 \mathrm{ng} / \mu \mathrm{l}$ of the coinjection marker ofm-1::gfp into wild-type worms, generating the two lines jxEx199 and jxEx201.

\section{Fluorescent in situ hybridization (FISH)}

The mRNA of different ILPs or GFP were all visualized by FISH. Worms were washed with sterile water and fixed for 45 min with $4 \%$ paraformaldehyde at room temperature, $\sim 22^{\circ} \mathrm{C}$ (Stewart et al., 2007). After 3 five-min washes with phosphate-buffered saline (PBS), fixed worms were placed on a nutator and treated with $70 \%$ ethanol for 5 hrs to overnight at $4^{\circ} \mathrm{C}$ (Tautz and Pfeifle, 1989). Hybridization with the appropriate probe set (1:500 dilution) in hybridization buffer (15\% deionized formamide, $10 \%$ dextran sulfate, $1 \mathrm{mg} / \mathrm{ml}$ E. coli tRNA, $4 \mathrm{mM}$ vanadyl ribonuleoside complex and $0.2 \mathrm{mg} / \mathrm{ml}$ RNase-free BSA) was performed for $16 \mathrm{hrs}$ in the dark at $30^{\circ} \mathrm{C}$, followed by multiple 2- 
or 3 -hr washes in $10 \%$ formamide in 2 X SSC buffer for a total period of $36 \mathrm{hrs}$ (Raj and Tyagi, 2010). The lower formamide concentration in the washes was to ensure retention of the signal during the washes. After the final wash, worms were kept at $4^{\circ} \mathrm{C}$ for 3 hours in $2 \mathrm{XSC}$ buffer before treatment with Prolong Diamond Antifade (ThermoFisher, cat \# P36961, refractive index of 1.47 ) for at least $24 \mathrm{hrs}$ at $4^{\circ} \mathrm{C}$.

All probes are labeled with CAL-Fluor 610 at the 3' end and were generated through the Stellaris RNA-FISH Probe Designer 2.0, using the highest specificity (non-specificity masking level 5) from LGC Biosearch Technologies (Petaluma, CA).

\section{Image analyses of hybridized worms}

Within a week of hybridization and Antifade-treatment, worms were mounted on $1 \%$ agarose pads and imaged on a Nikon Eclipse Ti-E or Ni-U microscope (Nikon Instruments Inc, Tokyo, Japan). Images were captured with a CooISNAP MYO or ES2 CCD camera (Photometrics, Arizona, USA). Fluorescence intensities were quantified through a built-in fluorescence quantification algorithm (NIS-Elements/Annotations and Measurements/Mean Average Fluorescence Intensity, Nikon Instruments Inc), after a region-of-interest (ROI) background subtraction. Exposure time was kept constant at 900 ms without any neutral-density filter for all fluorescence imaging studies. All FISH images were taken at 400X magnification using the Nikon 40X N2 oil objective.

\section{Confocal laser scanning microscopy and live-image analyses}

For live imaging of AMAN-2::YFP, well-fed L3 worms were mounted on $1 \%$ agarose pads with 5 mM sodium azide (Sigma-Aldrich, CAS No. 26628-22-8), whereas dauers were mounted on pads with $9 \mathrm{mM}$ sodium azide (Simpkin and Coles, 1981). All confocal images were taken at 400X magnification within 30-40 min of mounting the worms. 
Image acquisition. All confocal images and movies were acquired through a Leica laserscanning confocal system (SP8), using a diode laser of $488 \mathrm{~nm}$ at $5 \%$ power (with a selected gated band-width of 500-560 nm, according to the Dye-Assistant plug-in of the LAS-X software). To achieve maximum sensitivity, emitted signals are detected through a photomultiplier tube at $500 \mathrm{~nm}$. To obtain high signal-to-noise ratio from specimens, high-definition (1024 X $1024 \mathrm{dpi})$ images were scanned at a speed of $400 \mathrm{~Hz} / \mathrm{sec}$, with a line averaging of 4 . To achieve true confocality with minimum photo-bleaching, the pinhole aperture was set to 1 airy unit of the $40 \mathrm{X}$ oil objective with a smart-gain value of 630 .

To classify animals according to the amount of Golgi present in their dorsal cord axons, we used a particle-analyzer provided by FIJI (Schindelin et al., 2012). Animals with low axonal Golgi have less than 20 particles in a $50-\mu \mathrm{m}$ section of the dorsal cord; animals with a medium amount of axonal Golgi have 21-40 particles in a 50- $\mu \mathrm{m}$ section of the dorsal cord; and animals with high axonal Golgi have greater than 40 particles in a $50-\mu \mathrm{m}$ section of the dorsal cord.

Movie acquisition and $3 D$ reconstruction. Using the protocol described above for image acquisition, each animal was scanned from bottom to top at $0.27-\mu \mathrm{m}$ intervals to produce a stack of images, which were then bound together at three frames per second to produce a movie. To generate a 3D reconstructed image of an entire L3 or dauer larva from a 16-bit movie, we used the Leica 3D reconstruction program (LAS-X software; threshold $=20-120$ ), which eliminated noise and puncta clusters (Sibarita, 2005). We used a volume-rendering method at $100 \%$ opacity during the 3D reconstruction of each animal (Pawley, 2006).

\section{Dauer exit assays}

Dauer exit assays were performed according to Cornils et al. (2011). Eggs laid for $3-7 \mathrm{hrs}$ at $20^{\circ} \mathrm{C}$ were collected and shifted to $25^{\circ} \mathrm{C}$ to induce dauer arrest. Forty-eight hours after the egg-laying 
midpoint, plates were checked for dauer formation, which were then assessed daily to calculate the rate of dauer exit.

\section{Statistical Analyses}

All statistical analyses were performed using GraphPad Prism 7.0, except for dauer exit analyses. Wild-type ins-6 hybridization signals were analyzed using 2-way ANOVA and Bonferroni correction with $95 \%$ confidence interval. Chi-square test was also performed to compare the differences between the classes of dauer populations across wild-type and mutant animals. For dauer exit, which were analyzed in JMP 6 from SAS, Kaplan-Maier probabilities were calculated and the $P$-value estimates were based on logrank comparisons. $P<0.05$ was considered significant for all statistical comparisons.

\section{ACKNOWLEDGEMENTS}

We thank S. Mitani, the Caenorhabditis Genetics Center (funded by NIH P40 OD010440), S. Eimer, A. Fire, M. Goodman, and P. Sengupta for strains and molecular reagents used in this study. We also thank R. Lillich and R. Patten of Mager Scientific Inc, Dexter, MI, and D. DeSantis and L. Mayernik of MICR Facility of Wayne State University for advice on fluorescence microscopy and the confocal scanning system; and Alcedo lab members, M. Friedrich, D. Njus, and S. Todi for discussions of this study. This work was supported by the Thomas C. Rumble University Graduate Fellowship to R. C. and by Wayne State University and NIH (R01 GM108962) to J. A. 


\section{REFERENCES}

Alcedo, J, Zhang, Y. 2013. Molecular and cellular circuits underlying Caenorhabditis elegans olfactory plasticity. In Invertebrate Learning and Memory, R Menzel,P Benjamin, eds. (San Diego, CA: Elsevier Academic Press, Inc), pp. 112-123.

Banerjee, A, Shen, P-J, Ma, S, Bathgate, RAD, Gundlach, AL. 2010. Swim stress excitation of nucleus incertus and rapid induction of relaxin-3 expression via CRF1 activation.

Neuropharmacology 58: 145-155. DOI: https://doi.org/10.1016/j.neuropharm.2009.06.019

Bargmann, Cl, Horvitz, HR. 1991. Control of larval development by chemosensory neurons in Caenorhabditis elegans. Science 251: 1243-1246.

Bathgate, RA, Halls, ML, van der Westhuizen, ET, Callander, GE, Kocan, M, Summers, RJ. 2013. Relaxin family peptides and their receptors. Physiol Rev 93: 405-480. DOI:

\section{https://doi.org/10.1152/physrev.00001.2012}

Bedse, G, Di Domenico, F, Serviddio, G, Cassano, T. 2015. Aberrant insulin signaling in Alzheimer's disease: current knowledge. Front Neurosci 9: 204. DOI:

\section{https://doi.org/10.3389/fnins.2015.00204}

Bertrand, E, Chartrand, P, Schaefer, M, Shenoy, SM, Singer, RH, Long, RM. 1998. Localization of ASH1 mRNA particles in living yeast. Mol Cell 2: 437-445. DOI:

\section{https://doi.org/10.1016/S1097-2765(00)80143-4}

Blázquez, E, Velázquez, E, Hurtado-Carneiro, V, Ruiz-Albusac, JM. 2014. Insulin in the brain: its pathophysiological implications for states related with central insulin resistance, type 2 diabetes and Alzheimer's disease. Front Endocrinol 5: 161. DOI:

\section{https://doi.org/10.3389/fendo.2014.00161}

Blessing, EM, Reus, V, Mellon, SH, Wolkowitz, OM, Flory, JD, Bierer, L, Lindqvist, D, Dhabhar, F, Li, M, Qian, M, et al. 2017. Biological predictors of insulin resistance associated with posttraumatic stress disorder in young military veterans. Psychoneuroendocrinology 82: 91-97. DOI: https://doi.org/10.1016/j.psyneuen.2017.04.016 
Boucher, J, Kleinridders, A, Kahn, CR. 2014. Insulin receptor signaling in normal and insulinresistant states. Cold Spring Harb Perspect Biol 6: a009191. DOI:

\section{https://doi.org/10.1101/cshperspect.a009191}

Brenner, S. 1974. The genetics of Caenorhabditis elegans. Genetics 77: 71-94.

Brogiolo, W, Stocker, H, Ikeya, T, Rintelen, F, Fernandez, R, Hafen, E. 2001. An evolutionarily conserved function of the Drosophila insulin receptor and insulin-like peptides in growth control. Curr Biol 11: 213-221.

Broughton, SJ, Piper, MDW, Ikeya, T, Bass, TM, Jacobson, J, Driege, Y, Martinez, P, Hafen, E, Withers, DJ, Leevers, SJ, et al. 2005. Longer lifespan, altered metabolism, and stress resistance in Drosophila from ablation of cells making insulin-like ligands. Proc Natl Acad Sci USA 102: 3105-3110. DOI: https://doi.org/10.1073/pnas.0405775102

Brown, BD, Zipkin, ID, Harland, RM. 1993. Sequence-specific endonucleolytic cleavage and protection of mRNA in Xenopus and Drosophila. Genes Dev 7: 1620-1631. DOI:

\section{https://doi.org/10.1101/gad.7.8.1620}

Cao, J, Ni, J, Ma, W, Shiu, V, Milla, LA, Park, S, Spletter, ML, Tang, S, Zhang, J, Wei, X, et al. 2014. Insight into insulin secretion from transcriptome and genetic analysis of insulin-producing cells of Drosophila. Genetics 197: 175-192.

Chen, Z, Hendricks, M, Cornils, A, Maier, W, Alcedo, J, Zhang, Y. 2013. Two insulin-like peptides antagonistically regulate aversive olfactory learning in C. elegans. Neuron 77: 572-585. Chisholm, AD, Hutter, H, Jin, Y, Wadsworth, WG. 2016. The genetics of axon guidance and axon regeneration in Caenorhabditis elegans. Genetics 204: 849-882. DOI:

\section{https://doi.org/10.1534/genetics.115.186262}

Colón-Ramos, DA, Margeta, MA, Shen, K. 2007. Glia promote local synaptogenesis through UNC-6 (Netrin) signaling in C. elegans. Science 318: 103-106. DOI:

\section{https://doi.org/10.1126/science.1143762}


Cornils, A, Gloeck, M, Chen, Z, Zhang, Y, Alcedo, J. 2011. Specific insulin-like peptides encode sensory information to regulate distinct developmental processes. Development 138: 11831193. DOI: https://doi.org/10.1242/dev.060905

Dalley, BK, Golomb, M. 1992. Gene expression in the Caenorhabditis elegans dauer larva: Developmental regulation of Hsp90 and other genes. Dev Biol 151: 80-90. DOI: https://doi.org/10.1016/0012-1606(92)90215-3

Decker, CJ, Parker, R. 1995. Diversity of cytoplasmic functions for the 3' untranslated region of

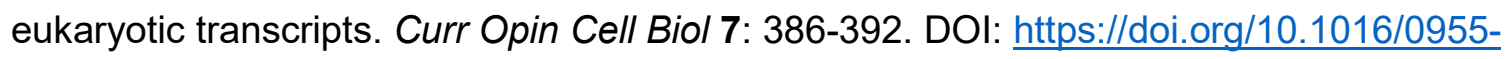

\section{$\underline{0674(95) 80094-8}$}

Edwards, SL, Yu, S-c, Hoover, CM, Phillips, BC, Richmond, JE, Miller, KG. 2013. An organelle gatekeeper function for Caenorhabditis elegans UNC-16 (JIP3) at the axon initial segment.

Genetics 194: 143-161. DOI: https://doi.org/10.1534/genetics.112.147348

Esch, T, Stefano, GB, Fricchione, GL, Benson, H. 2002. The role of stress in neurodegenerative diseases and mental disorders. Neuro Endocrinol Lett 23: 199-208.

Fernandes de Abreu, DA, Caballero, A, Fardel, P, Stroustrup, N, Chen, Z, Lee, K, Keyes, WD, Nash, ZM, López-Moyado, IF, Vaggi, F, et al. 2014. An insulin-to-insulin regulatory network orchestrates phenotypic specificity in development and physiology. PLoS Genet 10: e1004225e1004225. DOI: https://doi.org/10.1371/journal.pgen.1004225

Fernandez, AM, Torres-Aleman, I. 2012. The many faces of insulin-like peptide signalling in the brain. Nat Rev Neurosci 13: 225-239. DOI: https://doi.org/10.1038/nrn3209

Frey, $\mathrm{WH}, 2$ nd. 2013. Intranasal insulin to treat and protect against posttraumatic stress disorder. J Nerv Ment Dis 201: 638-639. DOI: https://doi.org/10.1097/NMD.0b013e318298302e Fu, Z, Gilbert, ER, Liu, D. 2013. Regulation of insulin synthesis and secretion and pancreatic Beta-cell dysfunction in diabetes. Curr Diabetes Rev 9: 25-53. 
Gems, D, Sutton, AJ, Sundermeyer, ML, Albert, PS, King, KV, Edgley, ML, Larsen, PL, Riddle, DL. 1998. Two pleiotropic classes of daf-2 mutation affect larval arrest, adult behavior, reproduction and longevity in Caenorhabditis elegans. Genetics 150: 129-155.

Golden, JW, Riddle, DL. 1984. The Caenorhabditis elegans dauer larva: developmental effects of pheromone, food, and temperature. Dev Biol 102: 368-378.

Gujar, MR, Stricker, AM, Lundquist, EA. 2017. Flavin monooxygenases regulate Caenorhabditis elegans axon guidance and growth cone protrusion with UNC-6/Netrin signaling and Rac GTPases. PLoS Genet 13: e1006998. DOI: https://doi.org/10.1371/journal.pgen.1006998 Gunkel, N, Yano, T, Markussen, F-H, Olsen, LC, Ephrussi, A. 1998. Localization-dependent translation requires a functional interaction between the $5^{\prime}$ and $3^{\prime}$ ends of oskar mRNA. Genes Dev 12: 1652-1664.

Holt, Christine E, Schuman, Erin M. 2013. The central dogma decentralized: new perspectives on RNA function and local translation in neurons. Neuron 80: 648-657. DOI:

\section{https://doi.org/10.1016/j.neuron.2013.10.036}

Jansen, RP. 2001. mRNA localization: message on the move. Nat Rev Mol Cell Biol 2: 247-256. DOI: https://doi.org/10.1038/35067016

Kanai, Y, Dohmae, N, Hirokawa, N. 2004. Kinesin transports RNA: isolation and characterization of an RNA-transporting granule. Neuron 43: 513-525. DOI:

\section{http://dx.doi.org/10.1016/j.neuron.2004.07.022}

Kao, G, Nordenson, C, Still, M, Rönnlund, A, Tuck, S, Naredi, P. 2007. ASNA-1 positively regulates insulin secretion in C. elegans and mammalian cells. Cell 128: 577-587.

Kaplan, REW, Maxwell, CS, Codd, NK, Baugh, LR. 2019. Pervasive positive and negative feedback regulation of insulin-like signaling in Caenorhabditis elegans. Genetics 211: 349-361. DOI: $\underline{\text { https://doi.org/10.1534/genetics.118.301702 }}$ 
Kim, S, Paik, Y-K. 2008. Developmental and reproductive consequences of prolonged nonaging dauer in Caenorhabditis elegans. Biochem Biophys Res Commun 368: 588-592.

Kimura, KD, Tissenbaum, HA, Liu, Y, Ruvkun, G. 1997. daf-2, an insulin receptor-like gene that regulates longevity and diapause in Caenorhabditis elegans. Science 277: 942-946.

Koenen, KC, Nugent, NR, Amstadter, AB. 2008. Gene-environment interaction in posttraumatic stress disorder: review, strategy and new directions for future research. Eur Arch Psychiatry Clin Neurosci 258: 82-96. DOI: https://doi.org/10.1007/s00406-007-0787-2

Kulkarni, RN, Brüning, JC, Winnay, JN, Postic, C, Magnuson, MA, Kahn, CR. 1999. Tissuespecific knockout of the insulin receptor in pancreatic $\beta$ cells creates an insulin secretory defect similar to that in type 2 diabetes. Cell 96: 329-339.

Lee, EK, Kim, W, Tominaga, K, Martindale, JL, Yang, X, Subaran, SS, Carlson, OD, Mercken, EM, Kulkarni, RN, Akamatsu, W, et al. 2012. RNA-binding protein HuD controls insulin translation. Mol Cell 45: 826-835. DOI: https://doi.org/10.1016/j.molcel.2012.01.016 Leibiger, IB, Leibiger, B, Moede, T, Berggren, P-O. 1998. Exocytosis of insulin promotes insulin gene transcription via the insulin receptor/PI-3 kinase/p70 S6 kinase and CaM kinase pathways. Mol Cell 1: 933-938. DOI: https://doi.org/10.1016/S1097-2765(00)80093-3

Li, W, Kennedy, SG, Ruvkun, G. 2003. daf-28 encodes a C. elegans insulin superfamily member that is regulated by environmental cues and acts in the DAF-2 signaling pathway.

Genes Dev 17: 844-858. DOI: https://doi.org/10.1101/gad.1066503

Lipton, DM, Maeder, Cl, Shen, K. 2018. Rapid assembly of presynaptic materials behind the growth cone in dopaminergic neurons is mediated by precise regulation of axonal transport. Cell Rep 24: 2709-2722. DOI: https://doi.org/10.1016/j.celrep.2018.07.096

Ma, S, Sang, Q, Lanciego, JL, Gundlach, AL. 2009. Localization of relaxin-3 in brain of Macaca fascicularis: identification of a nucleus incertus in primate. J Comp Neurol 517: 856-872. DOI: https://doi.org/10.1002/cne.22197 
Marcovecchio, ML, Chiarelli, F. 2012. The effects of acute and chronic stress on diabetes control. Sci Signal 5: pt10. DOI: https://doi.org/10.1126/scisignal.2003508

Messitt, TJ, Gagnon, JA, Kreiling, JA, Pratt, CA, Yoon, YJ, Mowry, KL. 2008. Multiple kinesin motors coordinate cytoplasmic RNA transport on a subpopulation of microtubules in Xenopus oocytes. Dev Cell 15: 426-436. DOI: http://dx.doi.org/10.1016/j.devcel.2008.06.014

Miranda-Vizuete, A, Fierro Gonzalez, JC, Gahmon, G, Burghoorn, J, Navas, P, Swoboda, P. 2006. Lifespan decrease in a Caenorhabditis elegans mutant lacking TRX-1, a thioredoxin expressed in ASJ sensory neurons. FEBS Lett 580: 484-490. DOI:

\section{https://doi.org/10.1016/j.febslet.2005.12.046}

Morest, DK. 1971. Dendrodendritic synapses of cells that have axons: the fine structure of the Golgi type II cell in the medial geniculate body of the cat. Z Anat Entwicklungsgesch 133: 216246.

Murphy, CT, McCarroll, SA, Bargmann, Cl, Fraser, A, Kamath, RS, Ahringer, J, Li, H, Kenyon, C. 2003. Genes that act downstream of DAF-16 to influence the lifespan of Caenorhabditis elegans. Nature 424: 277-283.

Pawley, JB. 2006. Handbook of biological confocal microscopy, 3rd edn (New York, NY: Springer).

Peden, EM, Barr, MM. 2005. The KLP-6 kinesin is required for male mating behaviors and polycystin localization in Caenorhabditis elegans. Curr Biol 15: 394-404. DOI:

\section{http://dx.doi.org/10.1016/j.cub.2004.12.073}

Pierce, SB, Costa, M, Wisotzkey, R, Devadhar, S, Homburger, SA, Buchman, AR, Ferguson, KC, Heller, J, Platt, DM, Pasquinelli, AA, et al. 2001. Regulation of DAF-2 receptor signaling by human insulin and ins-1, a member of the unusually large and diverse $C$. elegans insulin gene family. Genes Dev 15: 672-686. DOI: https://doi.org/10.1101/gad.867301

Raj, A, Tyagi, S. 2010. Detection of individual endogenous RNA transcripts in situ using multiple singly labeled probes. Methods Enzymol 472: 365-386. 10.1016/S0076-6879(10)72004-8 
Riddle, DL, Albert, PS. 1997. Genetic and Environmental Regulation of Dauer Larva Development. In C elegans II, nd, DL Riddle, T Blumenthal, BJ Meyer,JR Priess, eds. (Cold Spring Harbor (NY)).

Riddle, DL, Swanson, MM, Albert, PS. 1981. Interacting genes in nematode dauer larva formation. Nature 290: 668-671.

Sakamoto, R, Byrd, DT, Brown, HM, Hisamoto, N, Matsumoto, K, Jin, Y. 2005. The Caenorhabditis elegans UNC-14 RUN domain protein binds to the Kinesin-1 and UNC-16 complex and regulates synaptic vesicle localization. Mol Biol Cell 16: 483-496. DOI:

\section{https://doi.org/10.1091/mbc.E04-07-0553}

Schackwitz, WS, Inoue, T, Thomas, JH. 1996. Chemosensory neurons function in parallel to mediate a pheromone response in C. elegans. Neuron 17: 719-728.

Scheper, W, Meinsma, D, Holthuizen, PE, Sussenbach, JS. 1995. Long-range RNA interaction of two sequence elements required for endonucleolytic cleavage of human insulin-like growth factor II mRNAs. Mol Cell Biol 15: 235-245. DOI: https://doi.org/10.1128/mcb.15.1.235 Schindelin, J, Arganda-Carreras, I, Frise, E, Kaynig, V, Longair, M, Pietzsch, T, Preibisch, S, Rueden, C, Saalfeld, S, Schmid, B, et al. 2012. Fiji: an open-source platform for biologicalimage analysis. Nat Methods 9: 676-682. DOI: https://doi.org/10.1038/nmeth.2019 Scholey, JM. 2013. Kinesin-2: a family of heterotrimeric and homodimeric motors with diverse intracellular transport functions. Annu Rev Cell Dev Biol 29: 443-469. DOI:

\section{https://doi.org/10.1146/annurev-cellbio-101512-122335}

Schroeder, NE, Androwski, RJ, Rashid, A, Lee, H, Lee, J, Barr, MM. 2013. Dauer-specific dendrite arborization in C. elegans is regulated by KPC-1/Furin. Curr Biol 23: 1527-1535. Shen, K, Bargmann, Cl. 2003. The immunoglobulin superfamily protein SYG-1 determines the location of specific synapses in C. elegans. Cell 112: 619-630. DOI:

\section{https://doi.org/10.1016/S0092-8674(03)00113-2}

Sibarita, JB. 2005. Deconvolution microscopy. Adv Biochem Eng Biotechnol 95: 201-243. 
Siddiqui, SS. 2002. Metazoan motor models: kinesin superfamily in C. elegans. Traffic 3: 20-28. DOI: https://doi.org/10.1034/j.1600-0854.2002.30104.x

Simpkin, KG, Coles, GC. 1981. The use of Caenorhabditis elegans for anthelmintic screening. J Chem Technol Biotechnol 31: 66-69. DOI: https://doi.org/10.1002/jctb.503310110

Spaulding, EL, Burgess, RW. 2017. Accumulating evidence for axonal translation in neuronal homeostasis. Front Neurosci 11: 312.

Stewart, JC, Villasmil, ML, Frampton, MW. 2007. Changes in fluorescence intensity of selected leukocyte surface markers following fixation. Cytometry A 71: 379-385. DOI:

\section{https://doi.org/10.1002/cyto.a.20392}

Sumakovic, M, Hegermann, J, Luo, L, Husson, SJ, Schwarze, K, Olendrowitz, C, Schoofs, L, Richmond, J, Eimer, S. 2009. UNC-108/RAB-2 and its effector RIC-19 are involved in dense core vesicle maturation in Caenorhabditis elegans. J Cell Biol 186: 897-914. DOI:

\section{https://doi.org/10.1083/jcb.200902096}

Tabish, M, Kidwai Siddiqui, Z, Nishikawa, K, Siddiqui, SS. 1995. Exclusive expression of $C$. elegans osm-3 kinesin gene in chemosensory neurons open to the external environment. J Mol Biol 247: 377-389.

Tautz, D, Pfeifle, C. 1989. A non-radioactive in situ hybridization method for the localization of specific RNAs in Drosophila embryos reveals translational control of the segmentation gene hunchback. Chromosoma 98: 81-85.

Thio, GL, Ray, RP, Barcelo, G, Schupbach, T. 2000. Localization of gurken RNA in Drosophila oogenesis requires elements in the 5' and 3' regions of the transcript. Dev Biol 221: 435-446.

DOI: https://doi.org/10.1006/dbio.2000.9690

Wang, J, Kim, SK. 2003. Global analysis of dauer gene expression in Caenorhabditis elegans.

Development 130: 1621-1634. 
White, JG, Albertson, DG, Anness, MAR. 1978. Connectivity changes in a class of motoneurone during the development of a nematode. Nature 271: 764-766. DOI:

\section{https://doi.org/10.1038/271764a0}

White, JG, Southgate, E, Thomson, JN, Brenner, S. 1986. The structure of the nervous system of the nematode Caenorhabditis elegans. Philos Trans R Soc Lond B Biol Sci 314: 1-340.

Wigglesworth, VB. 1960. Axon structure and the dictyosomes (Golgi bodies) in the neurones of the cockroach, Periplaneta americana. J Cell Sci s3-101: 381-388.

Wilkinson, TN, Speed, TP, Tregear, GW, Bathgate, RA. 2005. Evolution of the relaxin-like peptide family: from neuropeptide to reproduction. Ann N Y Acad Sci 1041: 530-533. DOI:

\section{https://doi.org/10.1196/annals.1282.079}

Willis, DE, Xu, M, Donnelly, CJ, Tep, C, Kendall, M, Erenstheyn, M, English, AW, Schanen, NC, Kirn-Safran, CB, Yoon, SO, et al. 2011. Axonal localization of transgene mRNA in mature PNS and CNS neurons. J Neurosci 31: 14481-14487. DOI:

\section{https://doi.org/10.1523/JNEUROSCl.2950-11.2011}

Zeng, Y, Zhang, L, Hu, Z. 2016. Cerebral insulin, insulin signaling pathway, and brain angiogenesis. Neurol Sci 37: 9-16.

Zhao, $\mathrm{H}$, Nonet, ML. 2000. A retrograde signal is involved in activity-dependent remodeling at a C. elegans neuromuscular junction. Development 127: 1253-1266. 


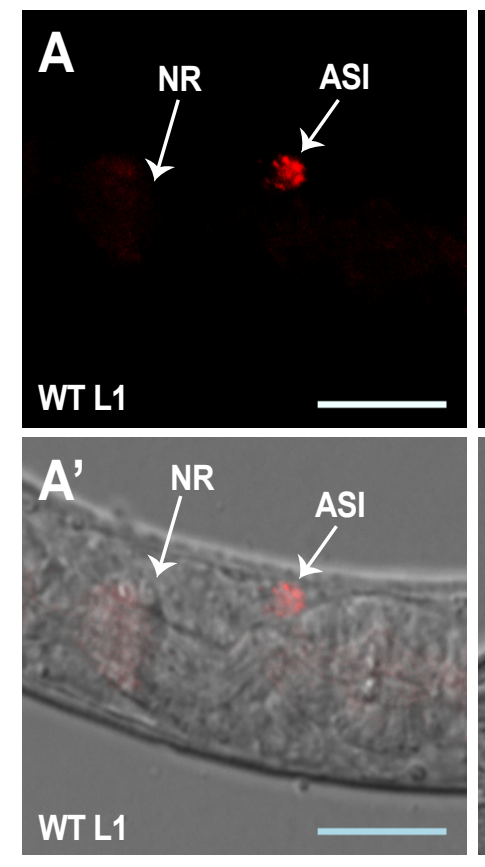

E

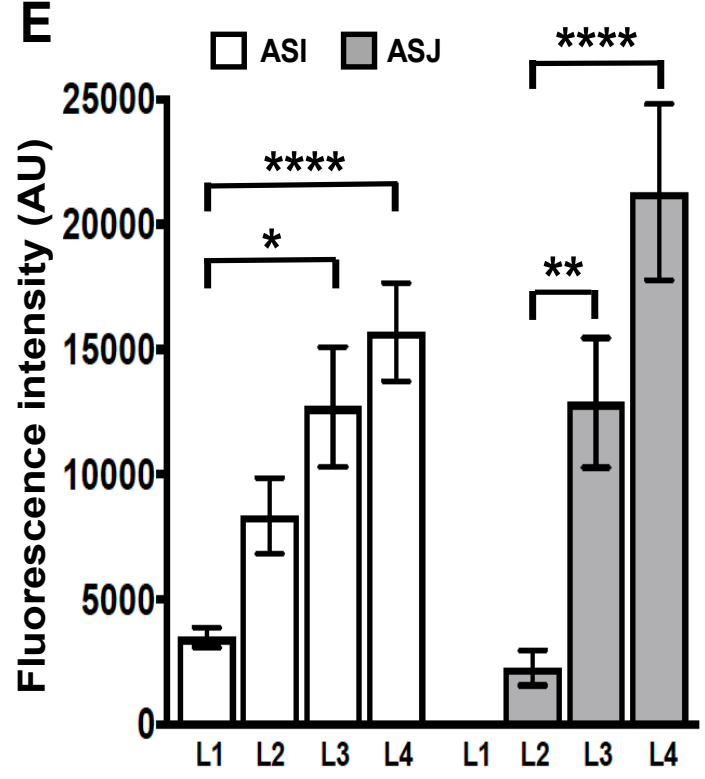

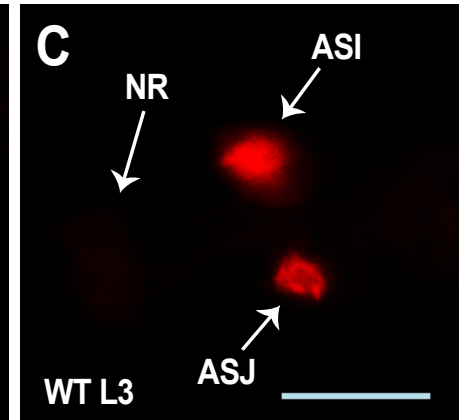

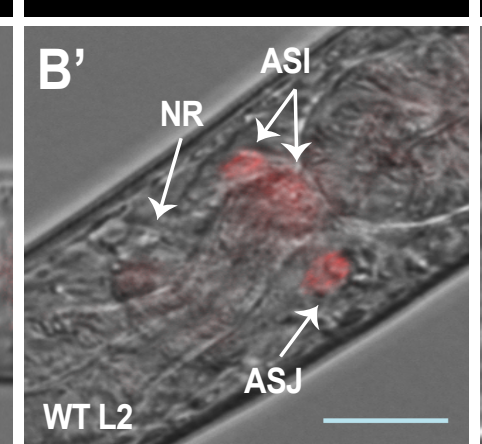

$F$

\begin{tabular}{|c|c|c|c|c|c|}
\hline \multirow{2}{*}{ stage } & \multicolumn{2}{|c|}{$\begin{array}{c}\text { \# of animals with } \\
\text { neuronal ins-6 mRNA }\end{array}$} & $\begin{array}{c}\text { mean total } \\
\text { ins-6 } \\
\pm \text { SEM }\end{array}$ & P vs L1 & $P$ vs L4 \\
\hline L1 & $24 / 24$ & $0 / 24$ & $\begin{array}{c}3481 \\
\pm 399\end{array}$ & - & $<0.0001$ \\
\hline L2 & $21 / 21$ & $2 / 21$ & $\begin{array}{c}10423 \\
\pm 2784\end{array}$ & ns & $<0.0001$ \\
\hline L3 & $23 / 23$ & $23 / 23$ & $\begin{array}{c}25679 \\
\pm 4583\end{array}$ & $<0.0001$ & 0.03 \\
\hline L4 & $22 / 22$ & $22 / 22$ & $\begin{array}{c}35166 \\
\pm 4121\end{array}$ & $<0.0001$ & - \\
\hline
\end{tabular}

Fig 1. The ILP ins-6 mRNA is expressed in the neuronal somas of wild-type larvae of the reproductive growth program. (A-D) show representative $\quad \mathrm{FISH}$ images of ins- 6 mRNA in the somas of $A S I$ and/or ASJ, while (A'-D') show fluorescence overlay on corresponding DIC images of L1 ( $A$ and $A^{\prime}$ ), L2 (B and $\left.\mathrm{B}^{\prime}\right)$, L3 (C and $\mathrm{C}^{\prime}$ ) and L4 (D and $D^{\prime}$ ) larvae at $20^{\circ} \mathrm{C}$. In this figure and later figures, anterior is to the left of each panel. Lateral views are shown, unless otherwise indicated. Scale bar is $10 \mu \mathrm{m}$. (E) Mean fluorescence intensities $( \pm$ SEM) of ins- 6 mRNA in ASI versus ASJ are from 2 trials. (F) Distribution of larvae that express ins- 6 mRNA in ASI and/or ASJ and the mean total intensities ( \pm SEM) of ins-6 mRNA fluorescence from 2 trials. Statistical significance is determined by two-way ANOVA and Bonferroni correction. WT, wild-type; NR, nerve ring; AU, arbitrary units; ns, not significant; * $P<0.05$; ${ }^{*}$, $P<0.01$; ${ }^{* * *}, P<0.0001$. 

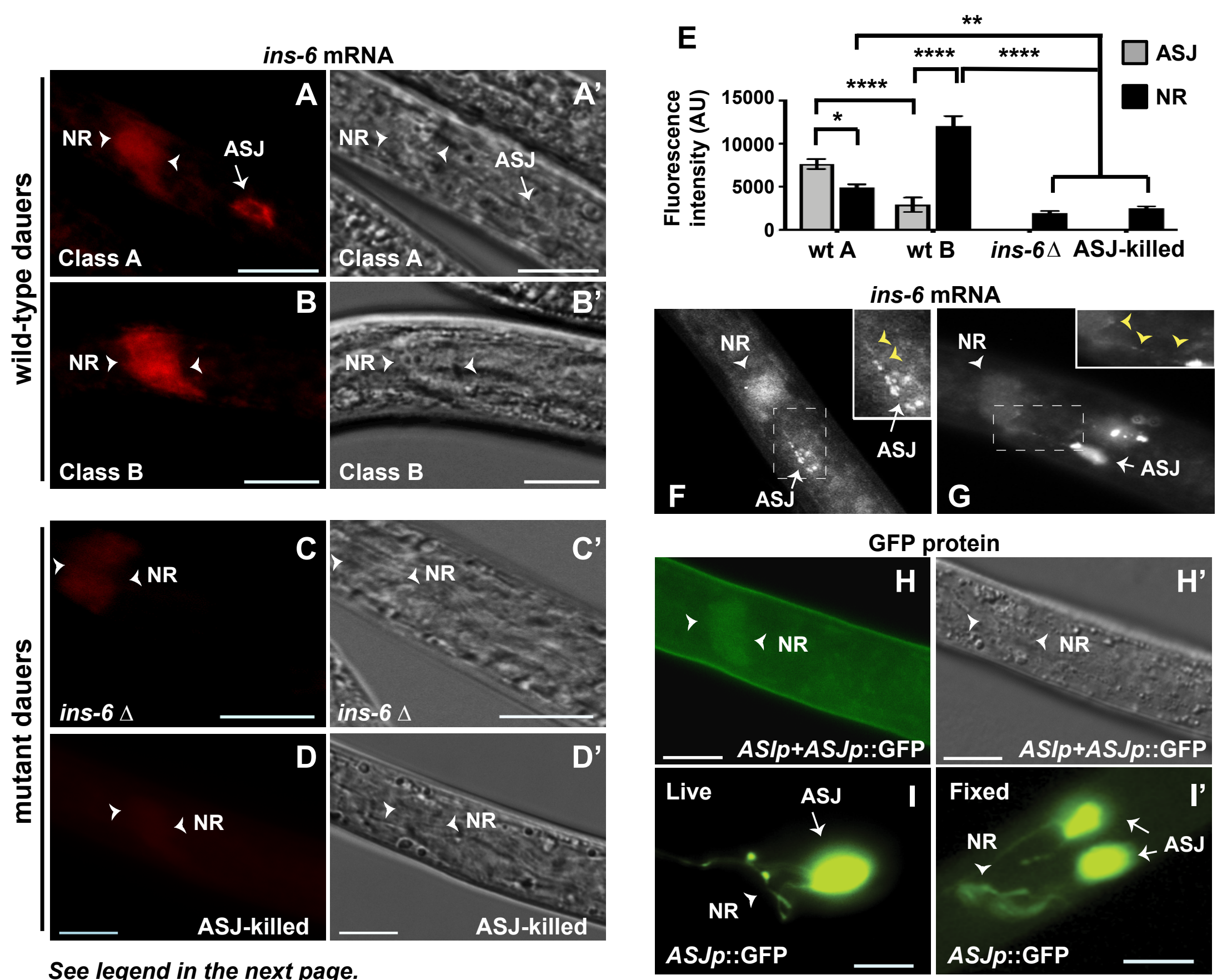

See legend in the next page. 
Fig 2. ins-6 mRNA is transported to the NR from ASJ in dauers. (A-B) are representative fluorescent images of ins-6 mRNA in the ASJ soma and/or NR of 5-day old dauers at $20^{\circ} \mathrm{C}$; ( $A^{\prime}-$ $\left.B^{\prime}\right)$ are the corresponding DIC images of A and B. (A-B and A'-B') are two classes of wild-type (wt) dauers based on ins-6 mRNA levels in axons vs soma. (C-D) show ins-6 mRNA fluorescent signals in mutant 5-day old dauers at $20^{\circ} \mathrm{C}$; (C'-D') are the corresponding DIC images of $\mathrm{C}$ and D. The ins- 6 mRNA signal is reduced to background in an ins-6(tm2416) deletion $(\Delta)$ mutant (C and $C^{\prime}$ ) and in a dauer that has ASJ-killed neurons (D and $\left.D^{\prime}\right)$. (E) Mean fluorescence intensities ( \pm SEM) of ins-6 mRNA in ASJ soma (grey bar) vs NR (black bar) from 3 trials. (F-G) FISH of ins-6 mRNA in wild-type ( $F$, lateral view) and ins-6-overexpressing ( $G$, ventrolateral view) dauers. Insets are magnified from dotted boxes in main panels. Yellow arrowheads in insets point to the mRNA signal in ASJ axons. (H) GFP protein fluorescence (green) in a dauer that expresses GFP in two pairs of neurons, ASI and ASJ. (H') Corresponding DIC image of $\mathrm{H}$. (I) Image of a live, untreated dauer that expresses GFP protein from the ASJ neuron pair. (I') Ventral view of a fixed and hybridization buffer-treated dauer that expresses GFP from the ASJ neuron pair, similar to I. Note the diffuse and broader GFP protein fluorescence from the NR (nerve ring) in this panel compared to the NR fluorescence in I. White arrowheads in A-D, A'-D', H-I, H'-l' point to the NR and/or its boundaries. AU, arbitrary units; ns, not significant; ${ }^{*}, P<0.05 ;{ }^{* *}, P<0.01$; ${ }^{* * *}, P<$ 0.0001 . Scale bar, $10 \mu \mathrm{m}$. 


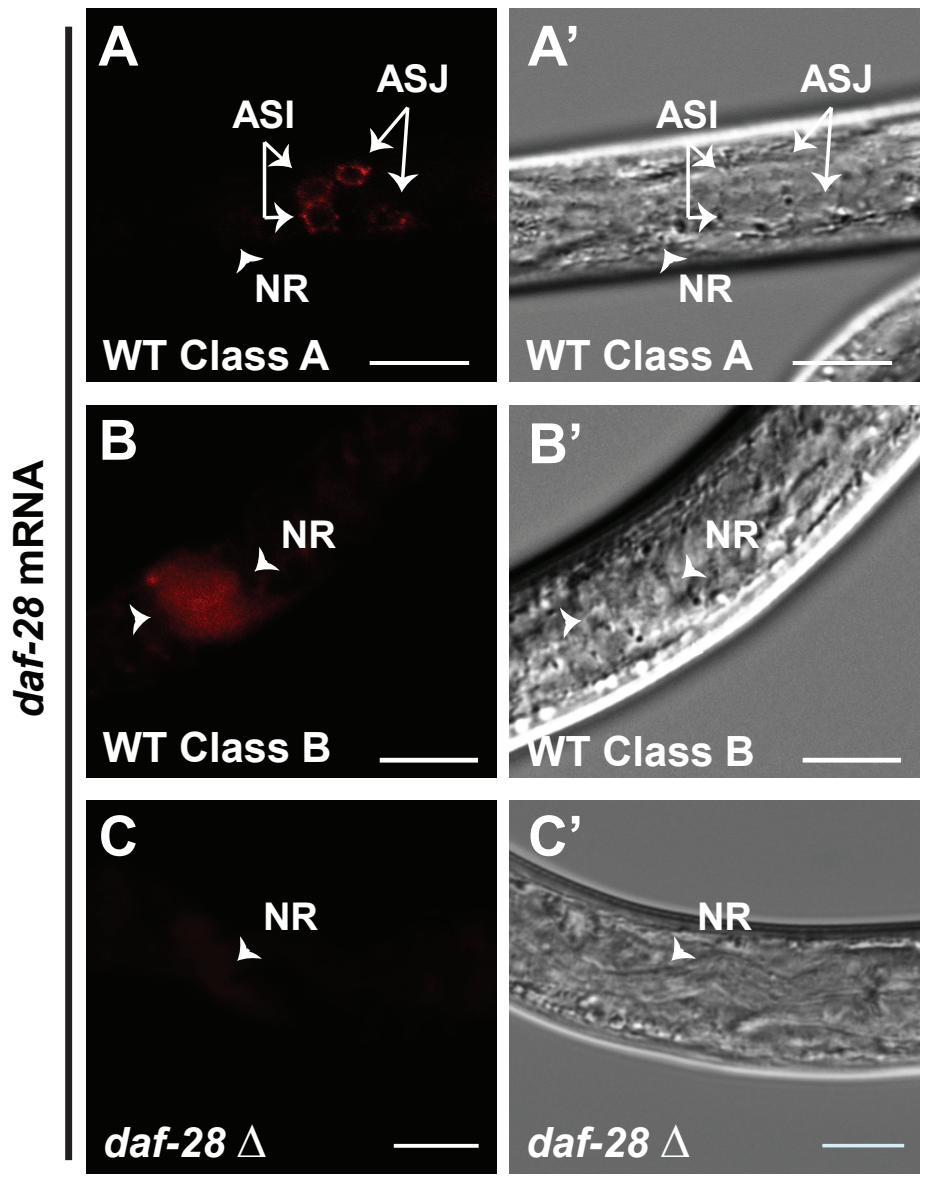

Fig 3. Exit-promoting ILP mRNAs are trafficked to dauer axons. (A-C) Fluorescent images of daf-28 mRNA in ASI and ASJ somas or NR. (A'-C') Corresponding DIC images at $20^{\circ} \mathrm{C}$ of 2-day (d) old WT (A-B) or daf-28(tm2308) deletion $(\Delta)$ mutant $(C)$ dauers. (A-B and $A^{\prime}-B^{\prime}$ ) Two classes of WT dauers based on daf-28 mRNA levels in axons vs somas. White arrowheads in A-C and A'-C' point to the NR and/or its boundaries. Scale bar, $10 \mu \mathrm{m}$. (D) Mean distribution ( \pm SEM) of 3 classes of 2- or 5 -d old WT dauers at $20^{\circ} \mathrm{C}$, based on specific ILP mRNA levels in somas vs NR. Class A dauers have more ILP mRNA in somas; class B, more ILP mRNA in NR; and class C, no expression in somas and NR. Number of WT dauers assayed: for daf-28 mRNA, 24 (2-d) and 26 (5-d); for ins-6, 28 (2-d) and 30 (5-d); and for ins-1, 30 (2-d) and 36 (5-d), from at least 2 trials. (E) Mean NR signals ( \pm SEM) of daf-28 or ins-6 mRNA in WT (from $D)$ or the corresponding ILP deletion $(\Delta)$ mutant dauers. Number of daf-28 $(\Delta)$ mutants assayed for daf-28 mRNA are 26 (2-d) and 25 (5-d); and ins-6( $\Delta)$ mutants for ins-6 mRNA, 25 (2-d) and 30 (5-d), from at least 2 trials. AU, arbitrary units. ${ }^{*}, P<0.05 ;{ }^{* *}, P<0.01$; ${ }^{* * *}, P<0.001$; ${ }^{* * *}$, $P<0.0001$.
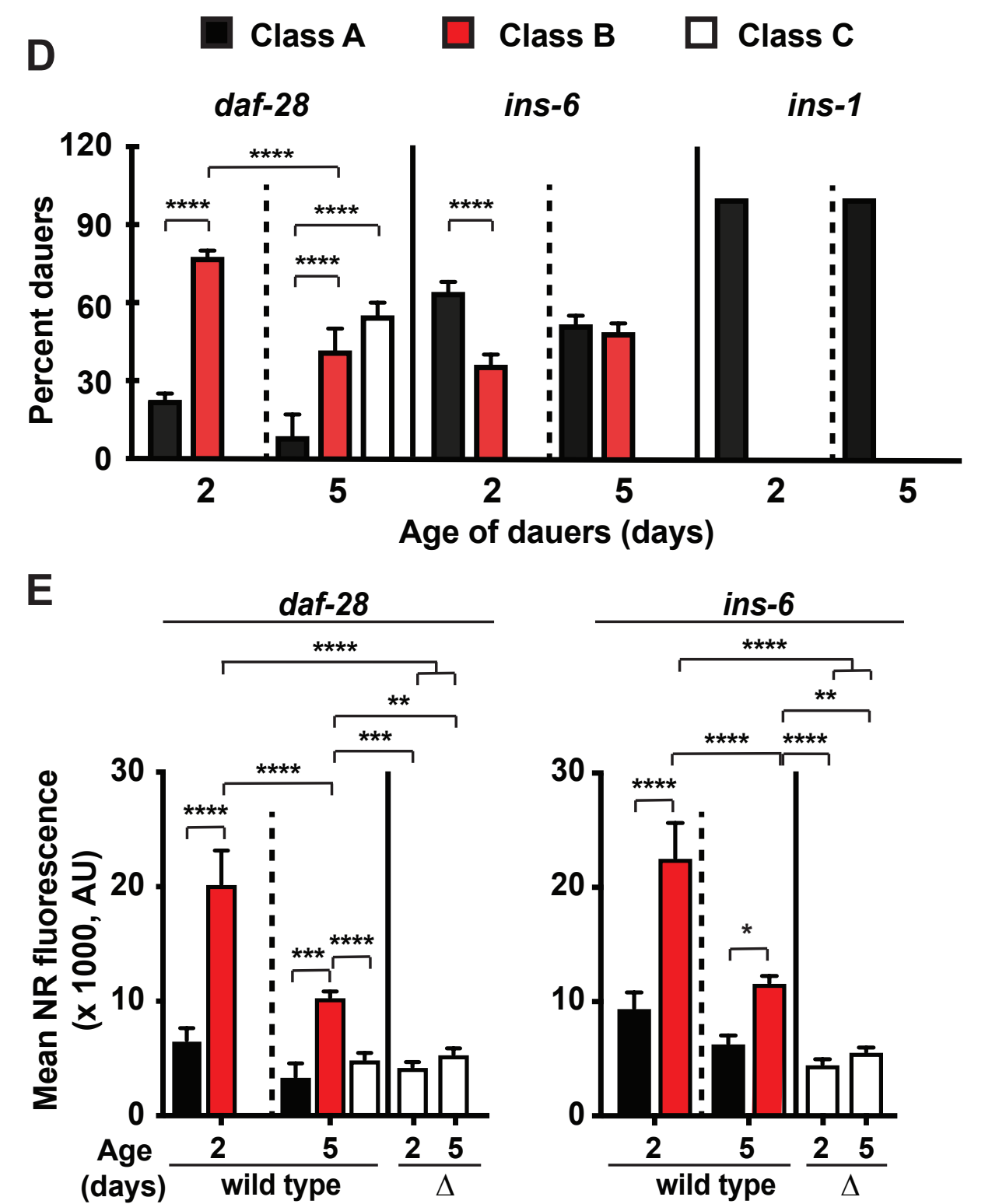


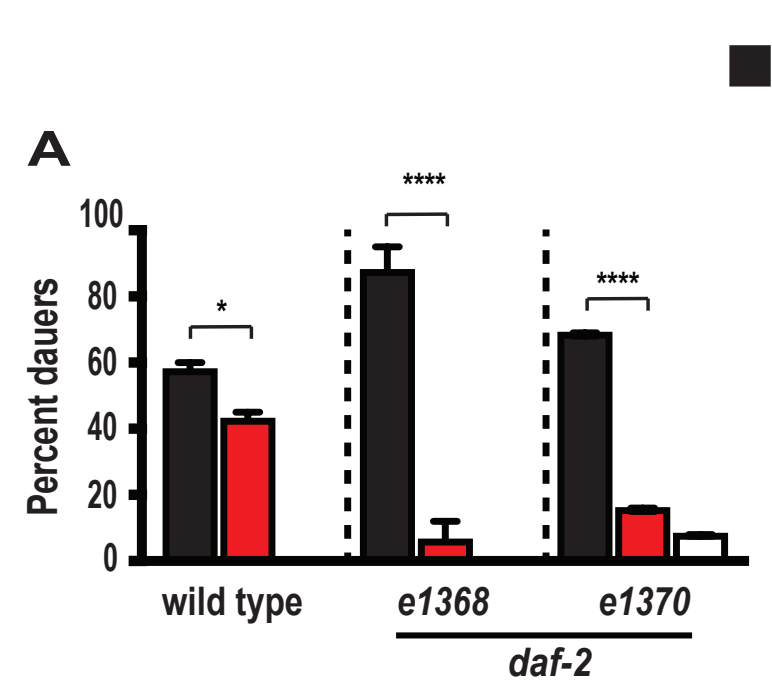

Class A $\square$ Class B $\square$ Class C
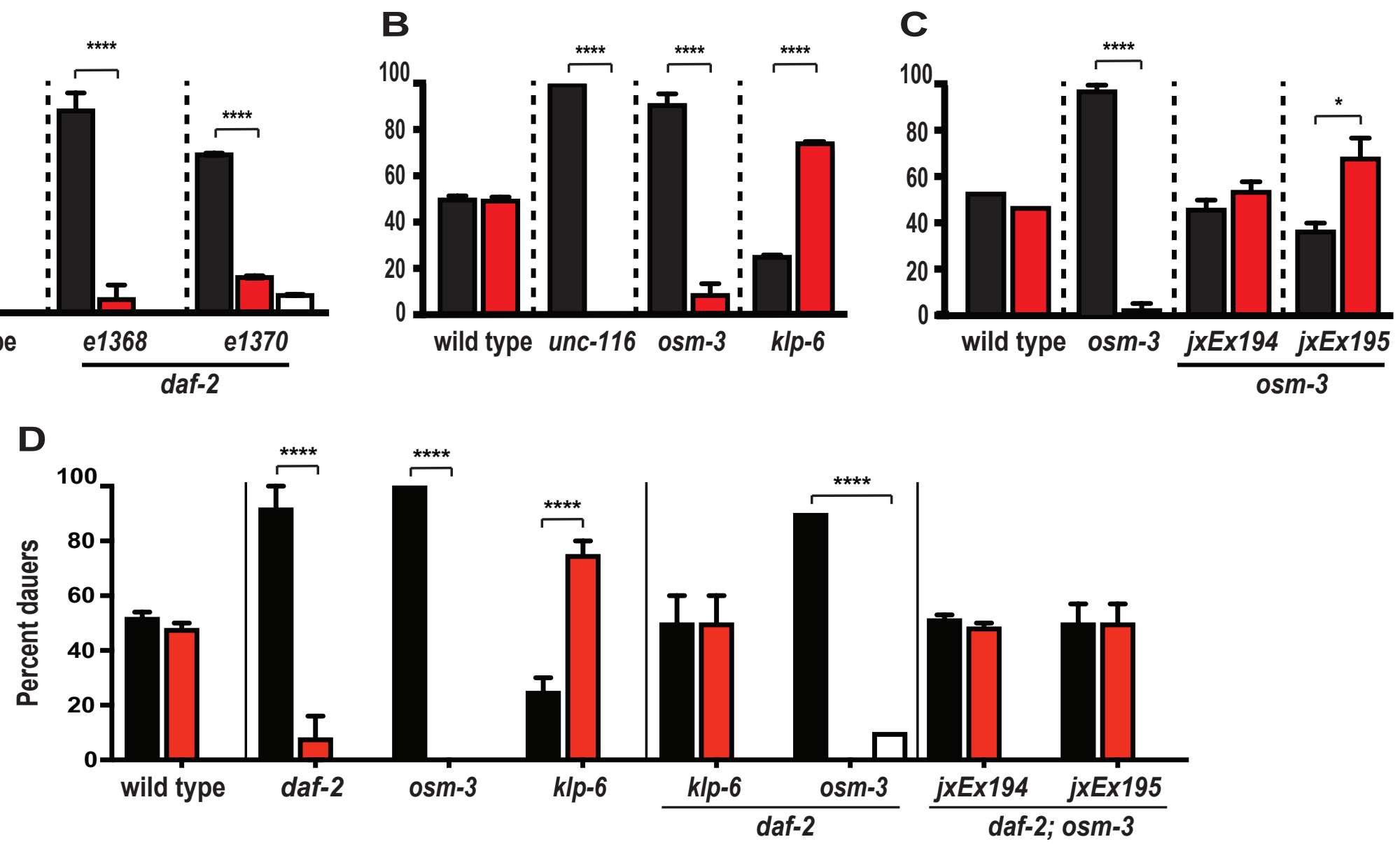

Fig 4. Insulin signaling and specific kinesins modulate axonal ins-6 mRNA levels. (A-D) Mean distribution ( \pm SEM) of three classes of wild-type or mutant dauers. In this figure and subsequent figures, class A dauers have more ins- 6 mRNA in the ASJ soma; class B, more ins-6 mRNA in the NR; and class C, no ins-6 expression in somas and NR. (A) The 3-day old dauers of daf-2 alleles, e1368 and e1370, compared to 3-day old wild-type dauers at $25^{\circ} \mathrm{C}$. (B) Different kinesin mutations, unc-116(e2310), osm-3(p802), and klp-6(sy511), have different effects on the axonal ins-6 mRNA of 5-day old dauers at $20^{\circ} \mathrm{C}$. (C) ASJ-specific expression of osm-3 (jxEx194 or jxEx195) rescues axonal ins-6 mRNA levels in 5-day old dauers at $20^{\circ} \mathrm{C}$. (D) osm-3(p802) or klp-6(sy511) in the daf-2(e1368) mutant background alters the axonal ins-6 mRNA phenotype of the daf-2 mutation in 3-day old dauers at $25^{\circ} \mathrm{C}$. ASJ-specific rescue of osm-3 (jxEx194 or jxEx195) in daf-2; osm-3 double mutants restores class B dauers. Statistical comparisons within each strain of animals are shown. See Figure S4 for statistical comparisons across different strains. ${ }^{*}, P<0.05 ;{ }^{* * * *}, P<0.0001$. 


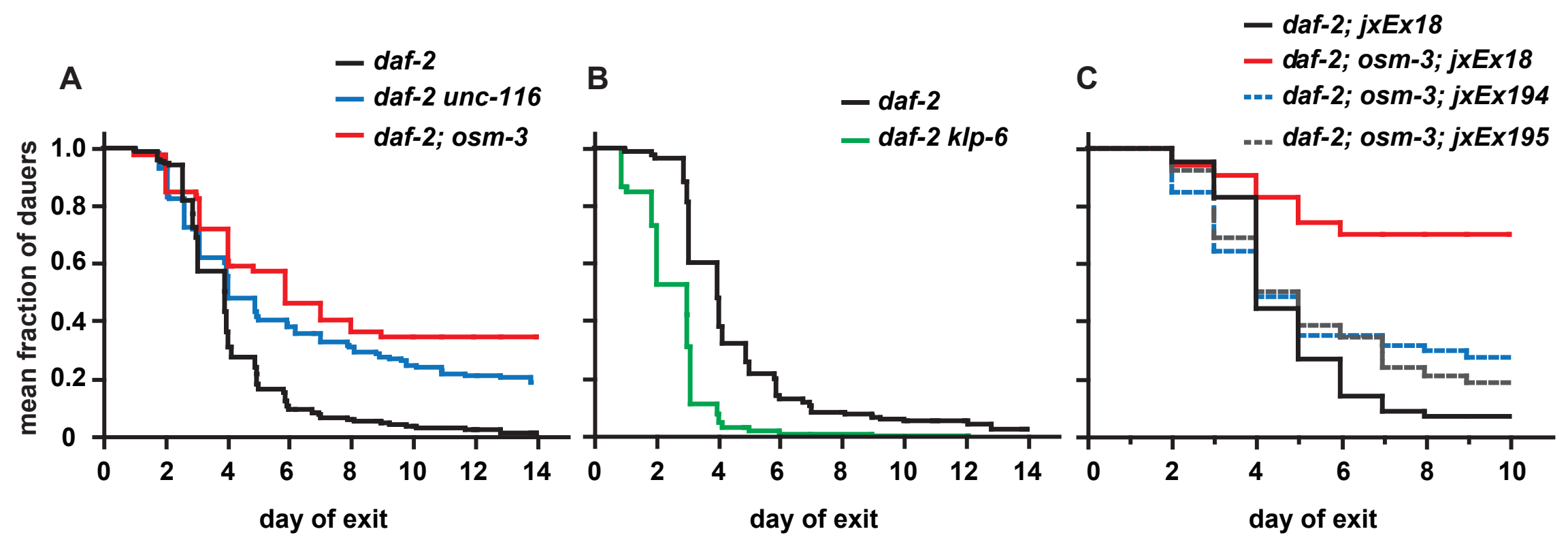

Fig 5. Axonal ins-6 mRNA facilitates stress recovery. (A-C) The dauer exit rates at $25^{\circ} \mathrm{C}$ of animals carrying different kinesin mutations, unc-116(e2310), osm-3(p802) or klp-6(sy511), in the daf-2(e1368) mutant background. (A-B) Animals that carry a kinesin mutation have a dauer exit rate that is significantly different from the daf-2(e1368) control by $P<0.0001$, according to the logrank test. Each curve represents cumulative data from 3-5 trials. (C) ASJ-specific rescue of osm-3 (jxEx194 or jxEx195) in daf-2; osm-3 double mutants restores dauer exit rates back to the daf-2(e1368) control, which carries the ofm-1::gfp coinjection marker (jxEx18) that is also present in jxEx194 or jXEx195. Each curve represents cumulative data from 2 trials. The complete statistical comparisons between the dauer exit phenotypes of the different groups of animals are shown in Table S1. 
A

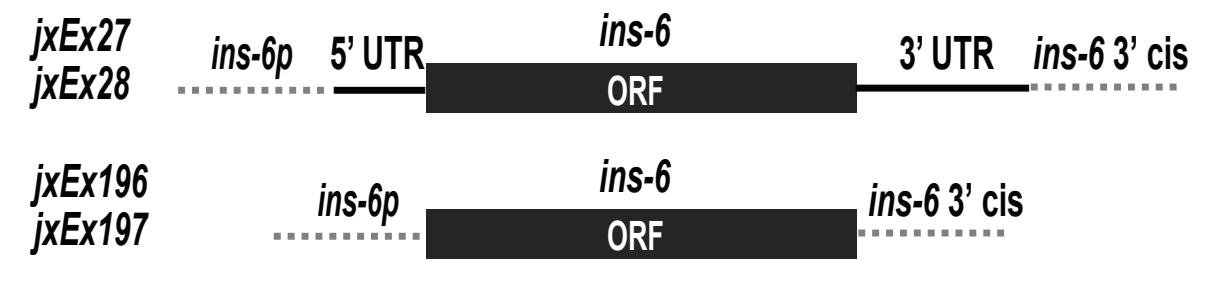

jXEx190 trx-1p
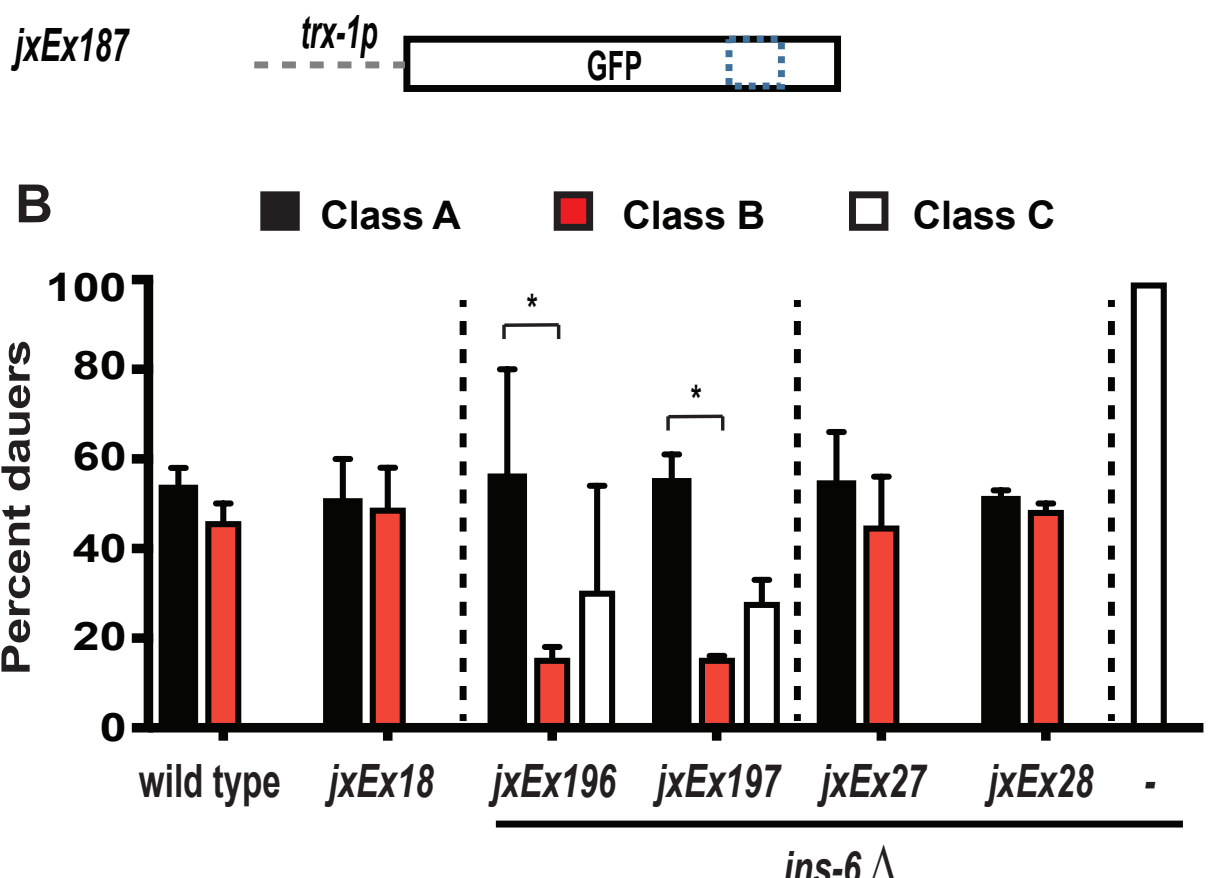
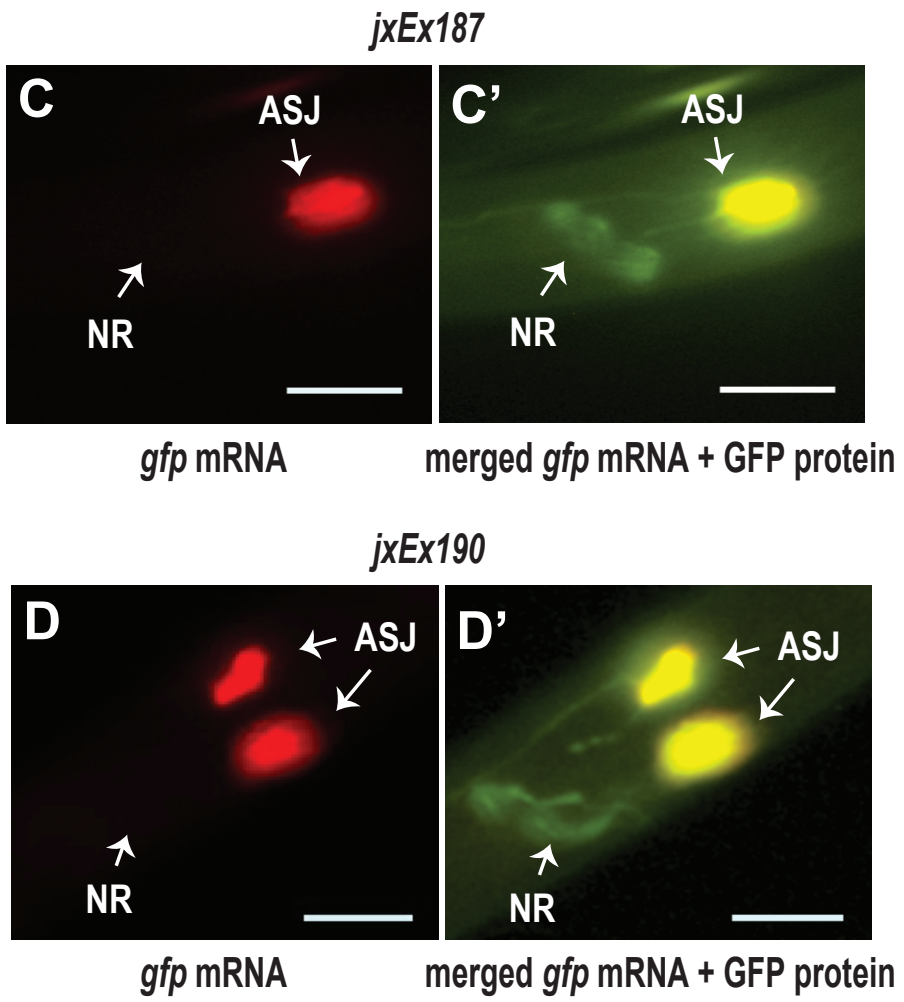

Fig 6. ins-6 UTR sequences are partly necessary, but insufficient to transport ins-6 mRNA axonally. (A) Diagrams of transgenes used. $j \times E \times 27$ or $j \times E \times 28$ is an ins- 6 rescuing transgene with the full ins-6 genomic locus (Cornils et al., 2011); $j \times E x 196$ or $j \times E x 197$, the ins-6 rescuing transgene lacking UTRs. $j \times E \times 190$ is a GFP cDNA flanked by the ins- 6 UTRs and specifically expressed in ASJ. jxEx187 is an ASJ-expressed GFP construct that lacks the ins-6 UTRs. The dotted box in GFP denotes its greater length than the ins-6 ORF. The dotted

lines of the ins- 6 or trx-1 promoter or ins-6 3' cis regulatory region indicate that they are not drawn to scale. (B) Mean distribution ( \pm SEM) at $20^{\circ} \mathrm{C}$ of three classes of wild-type or ins- 6 mutant 5-day old dauers that carry the indicated transgenes. jxEx18 depicts the ofm-1::gfp coinjection marker, which has no effect on the class distribution of dauers. The ins-6 transgenes (jxEx27, jxEx28, jxEx196 or jxEx197) were injected with the ofm-1::gfp coinjection marker into the ins-6(tm2416) deletion $(\Delta)$ mutant. Number of dauers assayed were 20-30 per strain. ${ }^{*}, P<$ 0.05. (C-D) gfp mRNA fluorescence in a 5-day old dauer that carries jxEx187 (C) or jxEx190 (D) at 20C. (C'-D') Merged mRNA (red) and protein (green) fluorescence of GFP in 5-day old dauers that carry the indicated transgenes. Yellow indicates colocalization of red and green fluorescence. Scale bar, $10 \mu \mathrm{m}$. 


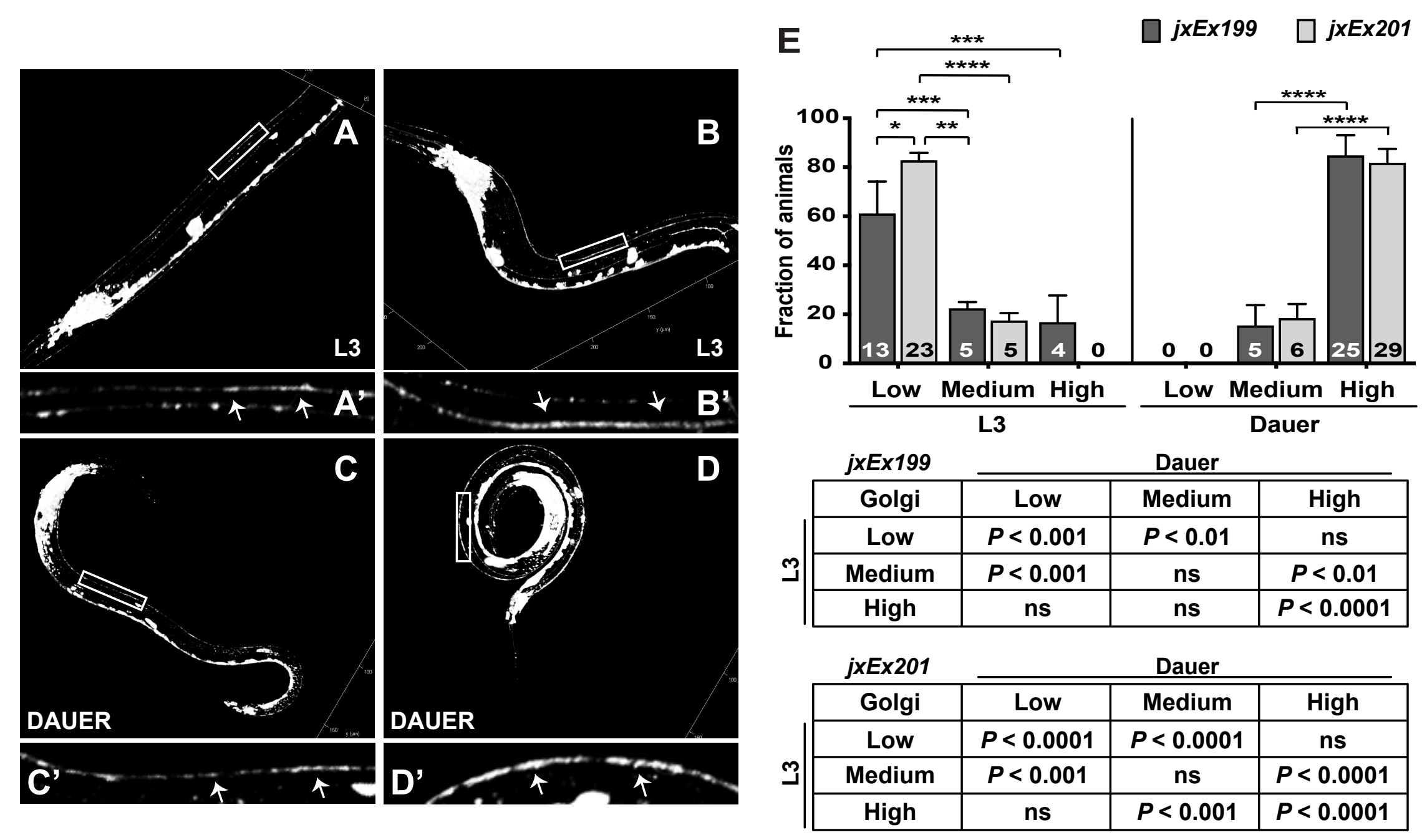

Fig 7. Stress enhances Golgi mobilization to the dorsal cord (DC) axons. (A-D) 3D-reconstruction of $j \times E x 199$ larvae that express the Golgi marker AMAN-2::YFP (Edwards et al., 2013; Sumakovic et al., 2009) at 20C. (A-B) L3 larvae with medium (A) or high (B) amounts of Golgi in DC axons. (A'-B') Higher magnification of a 50- $\mu \mathrm{m}$ section of the L3 DC axons (indicated by arrows; boxes in $A$ and B). (C-D) Dauers with medium (C) or high (D) amounts of Golgi in the DC axons. (C'-D') Higher magnification of a $50-\mu \mathrm{m}$ section of the dauer DC axons (indicated by arrows; boxes in C and D). (E) Mean fractions ( \pm SEM) of L3s and dauers that show different levels of Golgi bodies in DC axons from 3 trials, using 2 lines that express AMAN-2::YFP, jxEx199 and jxEx201. Tables show the statistical comparisons between L3s and dauers of each line. 